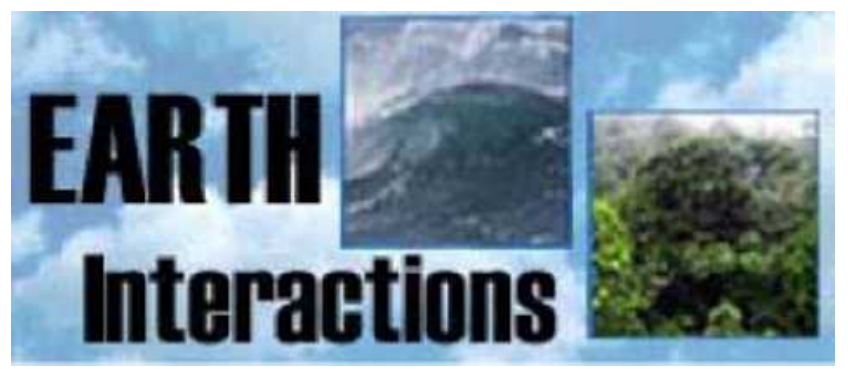

Copyright $\odot$ 2005, Paper 09-012; 9,559 words, 11 Figures, 2 Animations, 0 Tables. http://EarthInteractions.org

\title{
A Review of Current Investigations of Urban-Induced Rainfall and Recommendations for the Future
}

\section{J. Marshall Shepherd*}

\author{
Earth-Sun Exploration Division, NASA GSFC, Greenbelt, Maryland
}

Received 9 December 2004; accepted 16 February 2005

\begin{abstract}
Precipitation is a key link in the global water cycle and a proxy for changing climate; therefore, proper assessment of the urban environment's impact on precipitation (land use, aerosols, thermal properties) will be increasingly important in ongoing climate diagnostics and prediction, Global Water and Energy Cycle (GWEC) analysis and modeling, weather forecasting, freshwater resource management, urban planning-design, and landatmosphere-ocean interface processes. These facts are particularly critical if current projections for global urban growth are accurate.
\end{abstract}

The goal of this paper is to provide a concise review of recent (1990-present) studies related to how the urban environment affects precipitation. In addition to providing a synopsis of current work, recent findings are placed in context with historical investigations such as Metropolitan Meteorological Experiment (METROMEX) studies. Both observational and modeling studies of urbaninduced rainfall are discussed. Additionally, a discussion of the relative roles of urban dynamic and microphysical (e.g., aerosol) processes is presented. The paper closes with a set of recommendations for what observations and capabilities are needed in the future to advance our understanding of the processes.

KEYWORDS: Urban; Rainfall; Anthropogenic

* Corresponding author address: Dr. J. Marshall Shepherd, NASA GSFC, Code 613.1, Greenbelt, MD 20771.

E-mail address: marshall.shepherd@nasa.gov 
Earth Interactions - Volume 9 (2005) - Paper No. 12 - Page 2

\section{Introduction}

Urbanization is one of the extreme cases of land-use change. Although currently only $1.2 \%$ of the Earth's land is considered urban, the spatial coverage and density of cities are expected to rapidly increase in the near future. A recent paper by Elvidge et al. (Elvidge et al. 2004) indicated that the density of the impervious surface area (ISA) for the conterminous United States is $112610 \mathrm{~km}^{2}$, roughly the size of the state of Ohio and slightly larger than the area of herbaceous wetlands of the conterminous United States. It is estimated that by the year 2025, 60\% of the world's population will live in cities (UNFP 1999). Movie 1 is an illustration of the rapid growth of Phoenix, Arizona, over the last few decades. Though urban areas

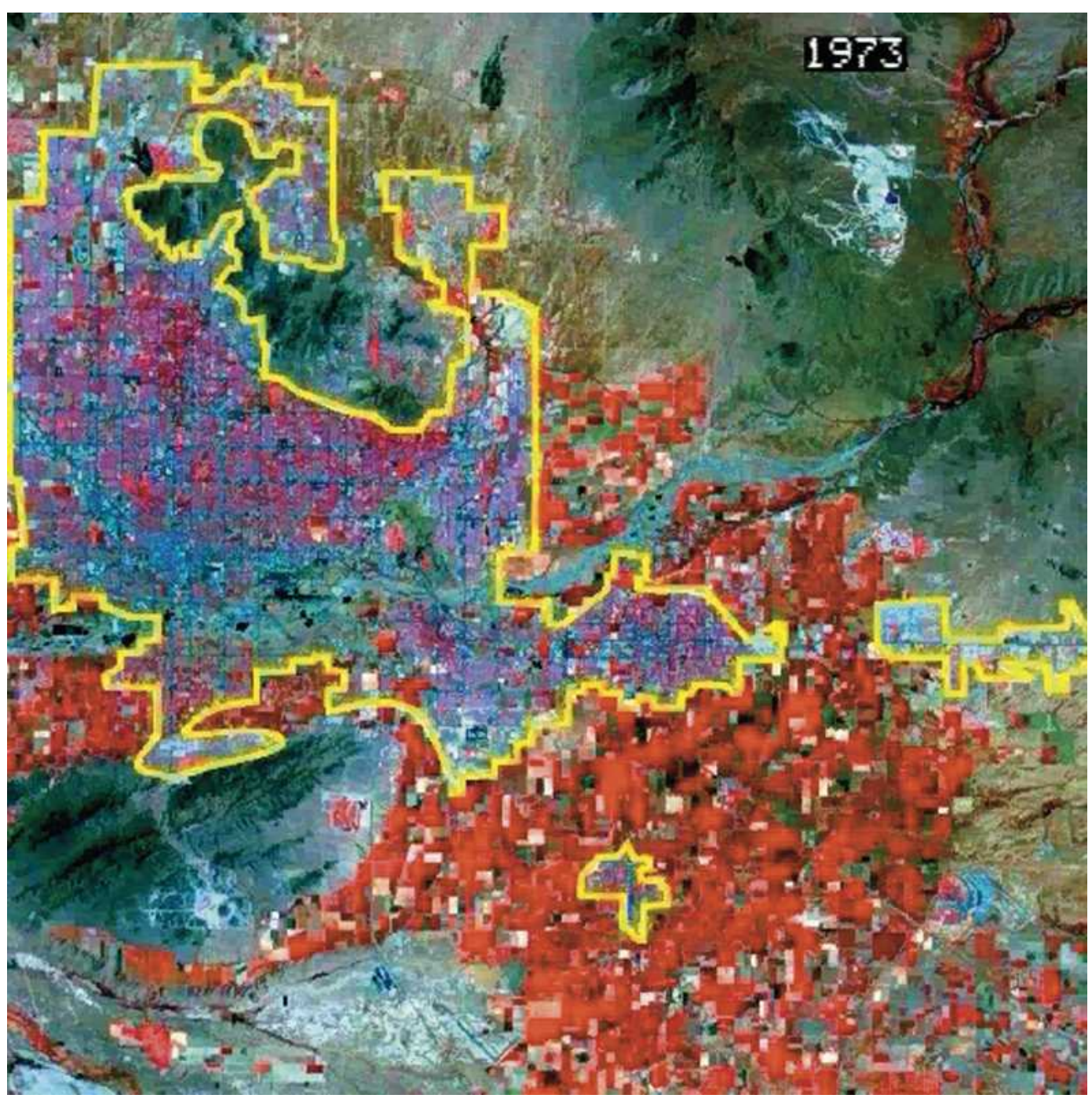

Movie 1. A quick-time movie illustrating the rapid growth of Phoenix, AZ, over the last few decades using a series of Landsat images.

See the online version of this paper to view animation. 
Earth Interactions - Volume 9 (2005) - Paper No. 12 - Page 3

are local in scale, human activity in urban environments has impacts at local to global scale by changing atmospheric composition, impacting components of the water cycle, and modifying the carbon cycle and ecosystems. However, our understanding of urbanization on the total Earth-climate system is incomplete. Better understanding of how the Earth's atmosphere-ocean-land-biosphere components interact as a coupled system and the influence of the urban environment on this climate system is critical (Figure 1).

As an example of recent concerns about the role of urban environments on the Earth system, several issues or questions raised in the United States' Climate Change Science Program plan (Climate Change Science Program and Subcommittee on Global Change Research 2003) echo the aforementioned statement about the urban environment-climate system linkage. A few examples include the following.

(i) How are land use and land cover linked to climate and weather?

(ii) How do climate variability and change affect land use and land cover, and what are the potential feedbacks of changes in land use and land cover to climate?

(iii) How do the primary and secondary pollutants from the world's megacities and large-scale, nonurban emissions (e.g., agriculture, ecosystems, etc.) contribute to global atmospheric composition?
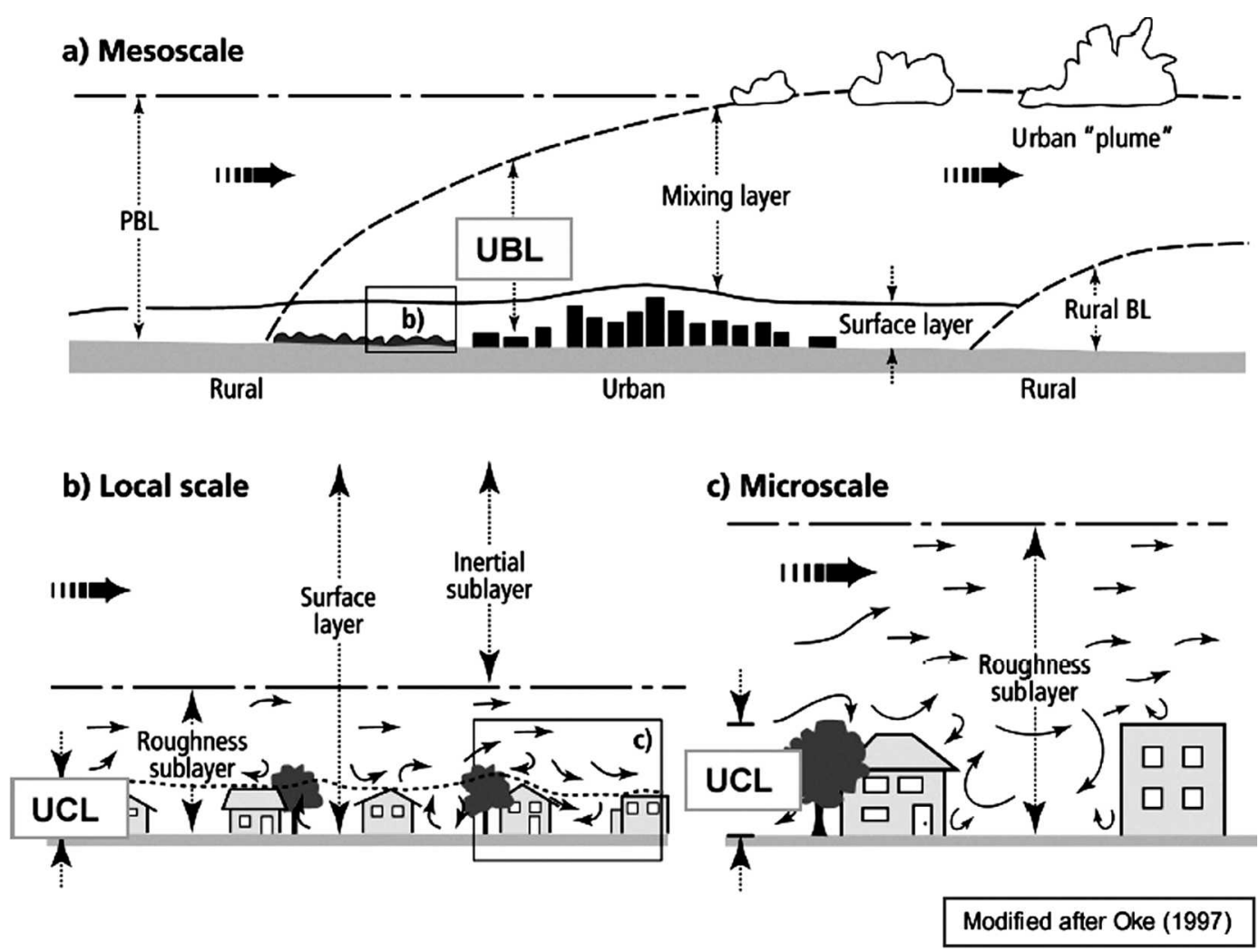

Figure 1. Various scales linking urban environments to the environmental system (modified after Oke (Oke 1987): urban canopy layer (UCL) and urban boundary layer (UBL)). 
Earth Interactions - Volume 9 (2005) - Paper No. 12 - Page 4

(iv) How are estimates of atmospheric composition and related processes to be used in assessments of the vulnerability of ecosystems to urban growth and long-range chemical transport?

(v) What research is required on the climatic effects of temperature on air quality, particularly in urban heat islands and other regional settings, and the potential health consequences?

Urban areas modify boundary layer processes in several ways. One of the primary mechanisms is through the creation of an urban heat island (UHI). In cities, natural land surfaces are replaced by artificial surfaces that have different thermal properties (e.g., heat capacity and thermal inertia). Such surfaces are typically more capable of storing solar energy and converting it to sensible heat. Other contributing factors to the onset of the UHI may be attributed to differences in surface albedo and anthropogenic heat release in the urban area. As sensible heat is transferred to the air, the temperature of the air in urban areas tends to be $2^{\circ}-10^{\circ} \mathrm{C}$ higher than surrounding nonurban areas. It is fairly well established that the positive heat anomaly is most evident on a clear and windless night with peaks in the late evening to early morning hours (Kim and Baik 2002). Arid urban areas like Phoenix can also exhibit a relatively weak UHI or and sometimes an urban heat sink because large amounts of energy are converted into latent heat rather than sensible heat because of the prevalence of irrigated lands (Diem and Brown 2003). The UHI intensity can exhibit diurnal and seasonal cycles and is modulated by cloud and wind conditions. Anthropogenically generated heat also affects UHI intensity. Although the magnitude (e.g., mean urban temperature - mean rural temperature) of the UHI is typically proportional to the city size (Oke 1981) and most apparent after sunset (Oke 1987), the UHI circulation is more clearly observed during the daytime than nighttime because of the urban-rural pressure gradient and vertical mixing during daytime hours (Shreffler 1978; Fujibe and Asai 1980). This fact has implications for why urban-forced convection is not simply a night-early morning phenomenon. To further understand the origins of the UHI, it is instructive to examine a surface heat budget equation:

$$
Q_{\mathrm{SW}}+Q_{\mathrm{LW}}+Q_{\mathrm{SH}}+Q_{\mathrm{LE}}+Q_{\mathrm{G}}+Q_{\mathrm{A}}=0 .
$$

In Equation (1), the terms are $Q_{\mathrm{SW}}$ (net shortwave irradiance), $Q_{\mathrm{LW}}$ (net longwave irradiance), $Q_{\mathrm{SH}}$ (surface sensible heat flux), $Q_{\mathrm{LE}}$ (latent turbulent heat flux), $Q_{\mathrm{A}}$ (anthropogenic heat input), and $Q_{\mathrm{G}}$ (ground heat conduction).

An equilibrium surface temperature is required for (1) to balance. At the surface, if no heat storage is permitted, differential heating results from horizontal gradients in one or more of the terms in (1). Spatial gradients in this equilibrium temperature in conjunction with the overlying thermodynamic and moisture stratification will dominate the upward or downward flux of heat for thermally forced systems, which results in horizontal temperature gradients required to drive a mesoscale circulation. In the case of the UHI, the difference in surface properties of urban and rural areas leads to the differences in the thermal fluxes in (1). Figure 2 is a qualitative description of the surface energy balance processes. Rural and urban systems obtain energy from radiative processes in which energy is gained from the sun and lost to the upper atmosphere and space. Shortwave radiation from the sun is absorbed only during the daytime, but the longwave radiation emitted by the 
Earth Interactions - Volume 9 (2005) • Paper No. 12 • Page 5

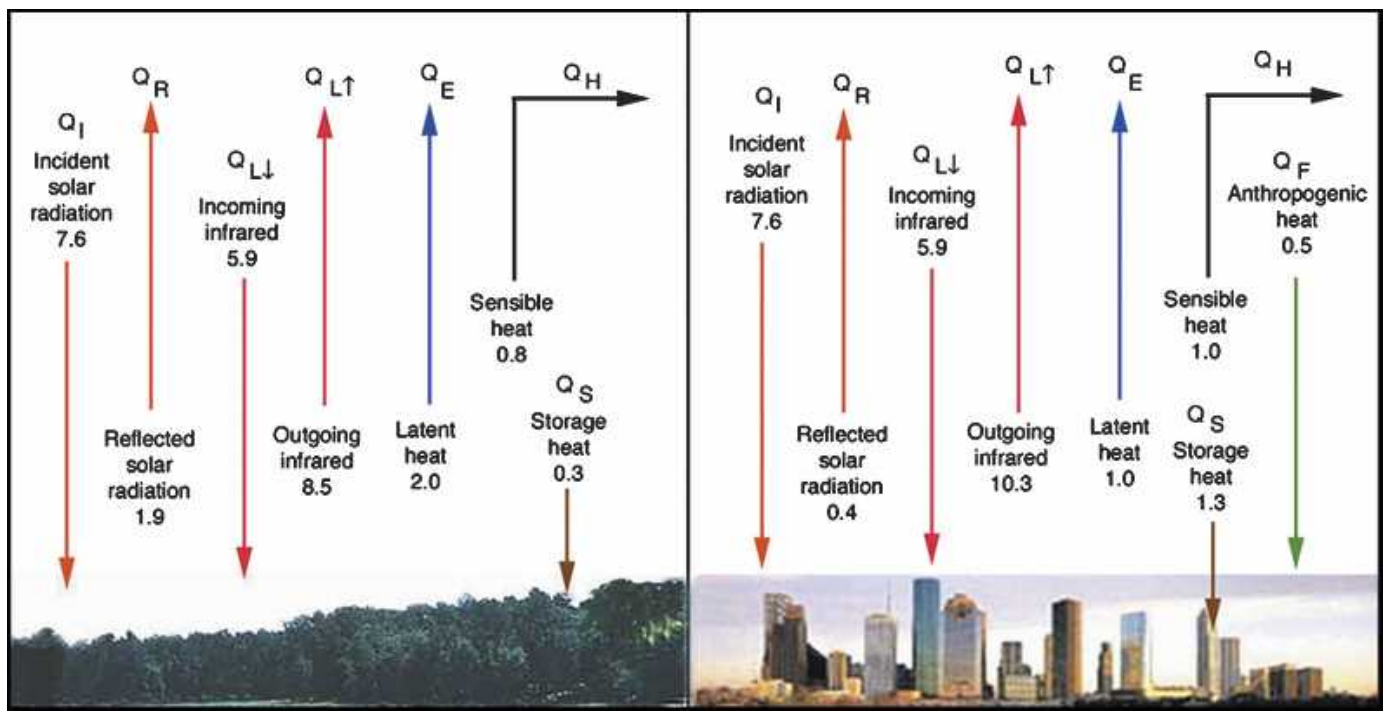

Figure 2. Typical rural and urban surface energy balance. The values are in units of kW h m ${ }^{2}$ day $^{-1}$ (courtesy of R. Sass, Rice University, online at http:// www.ruf.rice.edu/ sass/UHI.html).

Earth system is lost all the time. For example, in the figure, the incident solar radiation, QI, is $7.6 \mathrm{~kW} \mathrm{~h} \mathrm{~m}^{2}$ day $^{-1}$ for both locations because the same sun shines on both environments with equal intensity. With an albedo of 0.25 typical of a rural forest ecosystem, the reflected solar radiation, $\mathrm{QR}$, is $1.9 \mathrm{~kW} \mathrm{~h} \mathrm{~m} \mathrm{day}^{-1}$ in the country and $0.4 \mathrm{~kW} \mathrm{~h} \mathrm{~m}^{2}$ day $^{-1}$ in the city, which illustrates the urban environment's capacity to absorb more of the sun's energy than the rural ecosystem. Clearly, the differences in the reflected solar radiation, anthropogenic, latent heat, and outgoing infrared terms lead to heat islands and resulting thermal circulations. Figure 3 is an infrared image at $4 \mu \mathrm{m}$ identifying numerous urban heat island signatures (darker areas) associated with major cities in the eastern United States. Vukovich and Dunn (Vukovich and Dunn 1978) used a three-dimensional primitive equation model to show that heat island intensity and boundary layer stability have dominant roles in the development of heat island circulations. Additionally, Huff and Vogel (Huff and Vogel 1978) found that the urban circulation is primarily enhanced by the increased sensible heat fluxes and surface roughness of the urban area.

There is renewed debate on how the urban environment might affect precipitation variability. Possible mechanisms for urban environments to impact precipitation or convection include one or a combination of the following: 1) enhanced convergence due to increased surface roughness in the urban environment (e.g., Changnon et al. 1981; Bornstein and Lin 2000; Thielen et al. 2000), 2) destabilization due to UHI-thermal perturbation of the boundary layer and resulting downstream translation of the UHI circulation or UHI-generated convective clouds (e.g., Shepherd et al. 2002; Shepherd and Burian 2003), 3) enhanced aerosols in the urban environment for cloud condensation nuclei $(\mathrm{CCN})$ sources (e.g., Diem 


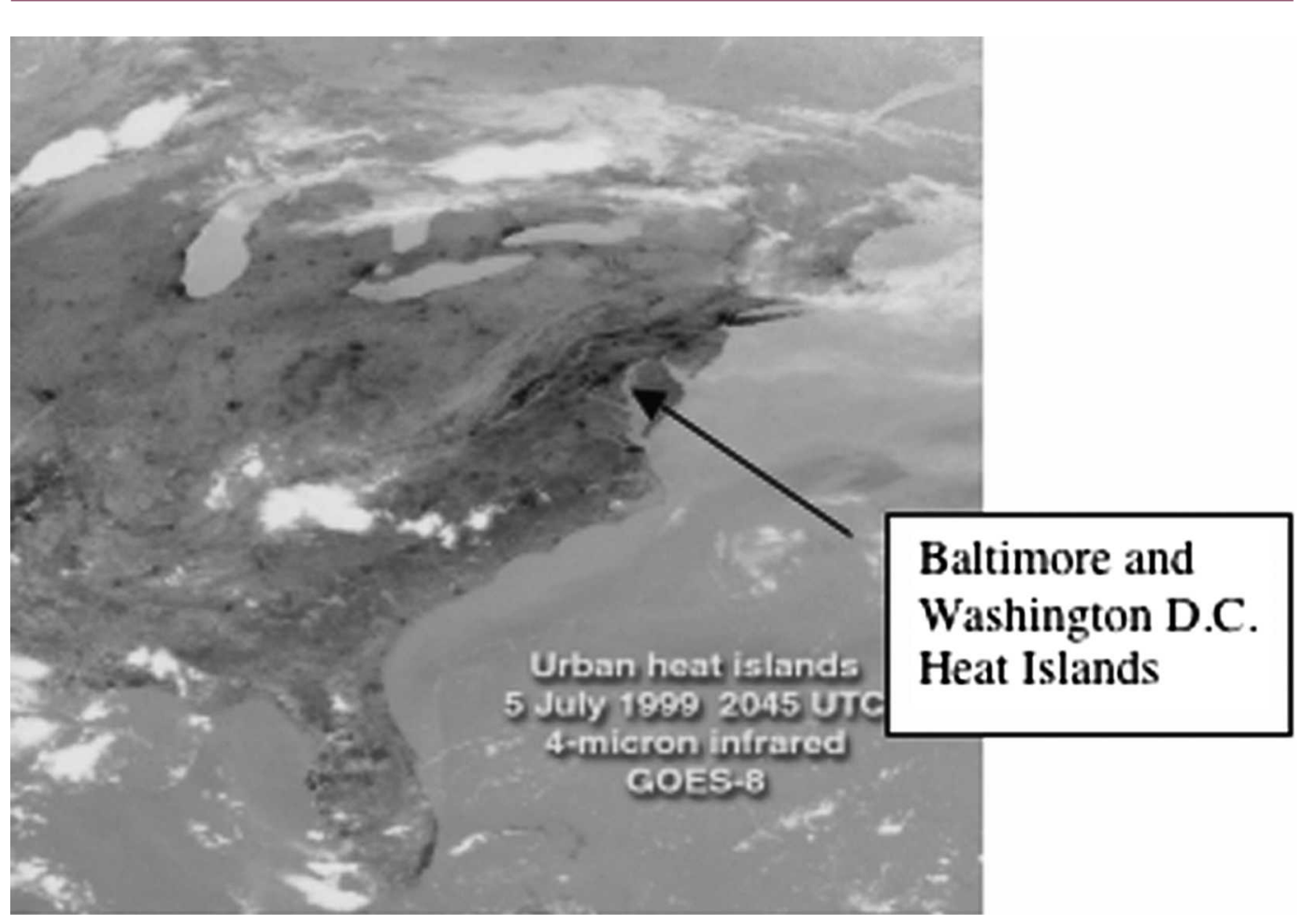

Figure 3. GOES-8 4- $\mu \mathrm{m}$ infrared channel indicating various urban heat islands (dark patches) in the eastern United States.

and Brown 2003; Molders and Olson 2004), or 4) bifurcating or diverting of precipitating systems by the urban canopy or related processes (e.g., Bornstein and Lin 2000; Loose and Bornstein 1977). Others have also hypothesized that urban areas serve as moisture sources needed for convective development (e.g., Dixon and Mote 2003).

More observational and modeling work is required to improve basic understanding of weather and climate impacts in the urban zone. This is particularly important since local-scale anthropogenic changes in weather and climate have a proportionally larger impact on the global population when they are associated with increases in population density. Recent international meetings in Lodz, Poland (2003), and Vancouver, British Columbia, Canada (2004), highlight the growing emphasis on understanding the role of the urban environment on the Earth's climate system (Shepherd and Jin 2004). To date, there is no conclusive answer to what mechanism dominates urban-induced precipitation process or what the relative role, if any, of each mechanism is. Furthermore, how the urban environment modifies these processes is also poorly understood. A synopsis of recent work addressing the impact of the urban environment on precipitation is offered. The intent of the discussion is to provide an overview of the most current and important studies on the topic and place it, where relevant, in the context of previous efforts. The section closes with a discussion of future requirements and direction needed to properly characterize and understand the problem. 


\section{Earth Interactions - Volume 9 (2005) - Paper No. 12 • Page 7 \\ 2. Historical perspective on urban effects on precipitation}

As early as 1921, Horton (Horton 1921) noted a tendency for thunderstorm formation over large cities rather than the rural environment. Work by Landsberg (Landsberg 1956) and Atkinson (Atkinson 1968) also noted potential impacts of large urban areas on rainfall patterns. In the past $30 \mathrm{yr}$, several observational and climatological studies have theorized that the UHI can have a significant influence on mesoscale circulations and resulting convection. Early investigations (Changnon 1968; Landsberg 1970; Huff and Changnon 1972) found evidence of warm seasonal rainfall increases of $9 \%$ to $17 \%$ over and downwind of major cities. The Metropolitan Meteorological Experiment (METROMEX) was an extensive study that took place in the 1970s in the United States (Changnon et al. 1977; Huff 1986) to further investigate modification of mesoscale and convective rainfall by major cities. In general, results from METROMEX have shown that urban effects lead to increased precipitation during the summer months. Increased precipitation was typically observed within and 50-75 km downwind of the city reflecting increases of 5\%-25\% over background values (Huff and Vogel 1978; Changnon 1979; Changnon et al. 1981; Braham et al. 1981; Changnon et al. 1991). Using a numerical model, Hjemfelt (Hjemfelt 1982) simulated the UHI of St. Louis, Missouri, and found positive vertical velocities downwind of the city. He suggested that the urban enhanced surface roughness convergence effect and the downwind shifting or enhancement of the UHI circulation by the synoptic flow were the cause. METROMEX results also suggested that areal extent and magnitude of urban and downwind precipitation anomalies were related to size of the urban area (Changnon 1992).

A second generation of studies continued to validate and extend the findings from pre- and post-METROMEX investigations. Balling and Brazel (Balling and Brazel 1987) observed more frequent late-afternoon storms in Phoenix during recent years of explosive population growth. Analysis by Bornstein and LeRoy (Bornstein and LeRoy 1990) found that New York City, New York, affects both summer daytime thunderstorm formation and movement. They illustrated that radar echo maxima were produced on the lateral edges and downwind of the city. Jauregui and Romales (Jauregui and Romales 1996) observed that the daytime heat island seemed to be correlated with intensification of rain showers during the wet season (May-October) in Mexico City, Mexico. They also presented an analysis of historical records showing that the frequency of intense rain showers has increased in recent decades in correlation with the growth of the city. Selover (Selover 1997) found similar results for moving summer convective storms over Phoenix. Changnon and Westcott (Changnon and Westcott 2002) found evidence of increasing heavy rainstorms in recent decades and suggested that intensity and frequency could continue to increase in the future.

\section{More recent observational studies of urban-induced precipitation variability}

It is becoming increasingly important to assess the role of urbanization on global Earth system processes as the Climate Change Science Program (Climate Change Science Program and Subcommittee on Global Change Research 2003) has iden- 
tified land use and aerosols (i.e., typical of urbanization) as factors of high uncertainty. Temperature changes are the primary topic in the climate change debate, but one of the most important potential impacts of a changing Earth system will be possible effects on global precipitation patterns and the frequency of severe droughts and floods. Dai et al. (Dai et al. 1997) have compiled long-term precipitation data into a form that removes inherent problems caused by the stochastic, nonhomogenous, and spurious nature of precipitation (Dai et al. 1997). Figure 4 (right) indicates that significant portions of the globe have become wetter over the last century. It is not clear what order of magnitude urban-induced precipitation variability accounts for, but it is probably not trivial. This growth mirrors the rapid growth of urban environments around the globe on the continents of Europe, Asia, and Africa. Many of these cities have experienced rapid growth in the last 30-40 yr (Figure 4) as indicated by the satellite image of global urban lights at night. Most of the studies related to urban-induced precipitation have come during a period of rapid global urban growth and observable changes in rainfall trends. Recent studies continue to provide evidence that urban environments can modify or induce precipitation under a specific set of conditions. Inoue and Kimura (Inoue and Kimura 2004) used National Oceanic and Atmospheric Administration (NOAA) satellite images to show that the frequency of low-level clouds is enhanced over the Tokyo, Japan, metropolitan area in the early afternoon. They suggested that low-level clouds form at the top of thermals in the mixed layer enhanced by stronger sensible heat flux in the urban area. Changnon (Changnon 2003) analyzed a database of freezing-rain occurrences during the period of 19452000 and found that freezing-rain occurrences in large cities are decreased by $10 \%-30 \%$ because of the heat island. The cities in his study included Chicago, Illinois; New York City; St. Louis; and Washington, D.C.

More directly related to precipitation processes, Takahashi (Takahashi 2003) presented evidence confirming previous literature studies that identified an increase in the frequency of occurrence of heavy rainfall in the Tokyo area in recent decades. The study by Fujibe (Fujibe 2003) linked increase surface convergence over the urban area to enhanced convection over major Japanese cities like Tokyo. Diem and Brown (Diem and Brown 2003) found that anthropogenic activities in the arid Phoenix area appear to have positively affected summer precipitation totals in downwind areas, particularly the Lower Verde basin. This study offered no conclusive evidence of a possible cause, but they suggested that the responsible enhancement mechanisms may include 1) increased surface-to-atmosphere transfer of water vapor due to irrigation; 2) increased convergence due to urban roughness and irrigation-induced circulations, or increased urban aerosols serving as CCN. This author extended this work by using a 108-yr data rain gauge record dating back to the 1890 s to establish that the Phoenix anomaly has only appeared in the posturban period of 1950-2003. Their results showed statistically significant increases in summer monsoon season rainfall of $11 \%-14 \%$ in the Lower Verde basin whereas other stations, including high terrain sites, had not experienced significant increases from the preurban to posturban period. We also used satellite rainfall estimates to identify the anomaly even during the severe drought period of 2003 (Figure 5, left). Shepherd's satellite analysis also revealed that summer monsoon storms that form in the mountains east of Phoenix often propagate westward toward the city. Shepherd hypothesized that convection-induced outflow 

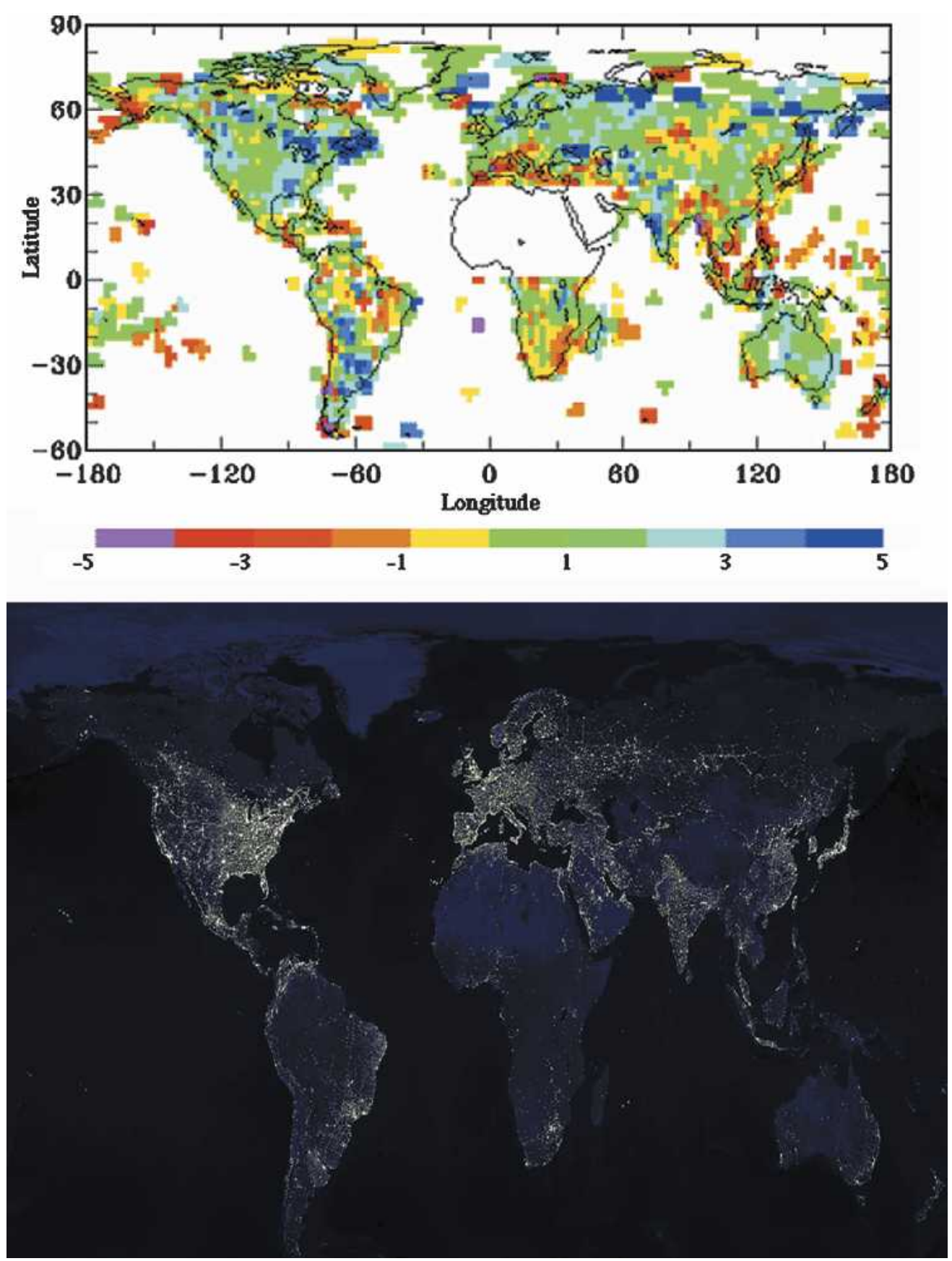

Figure 4. (†op) Long-term precipitation trends observed during 1900-88; green/blue indicate places that have become relatively wetter, and yellow/orange/ red indicate locations that have become relatively drier than the mean. The northern half of Africa is omitted because its dominant long-term trend is the Sahelian drought of the past few decades, a phenomenon distinct from the century-long trends seen elsewhere in the world (following Dai et al. 1997). (bottom) Satellite image of urban lights at night (courtesy of Defense Department and NASA). 
Earth Interactions - Volume 9 (2005) - Paper No. 12 • Page 10

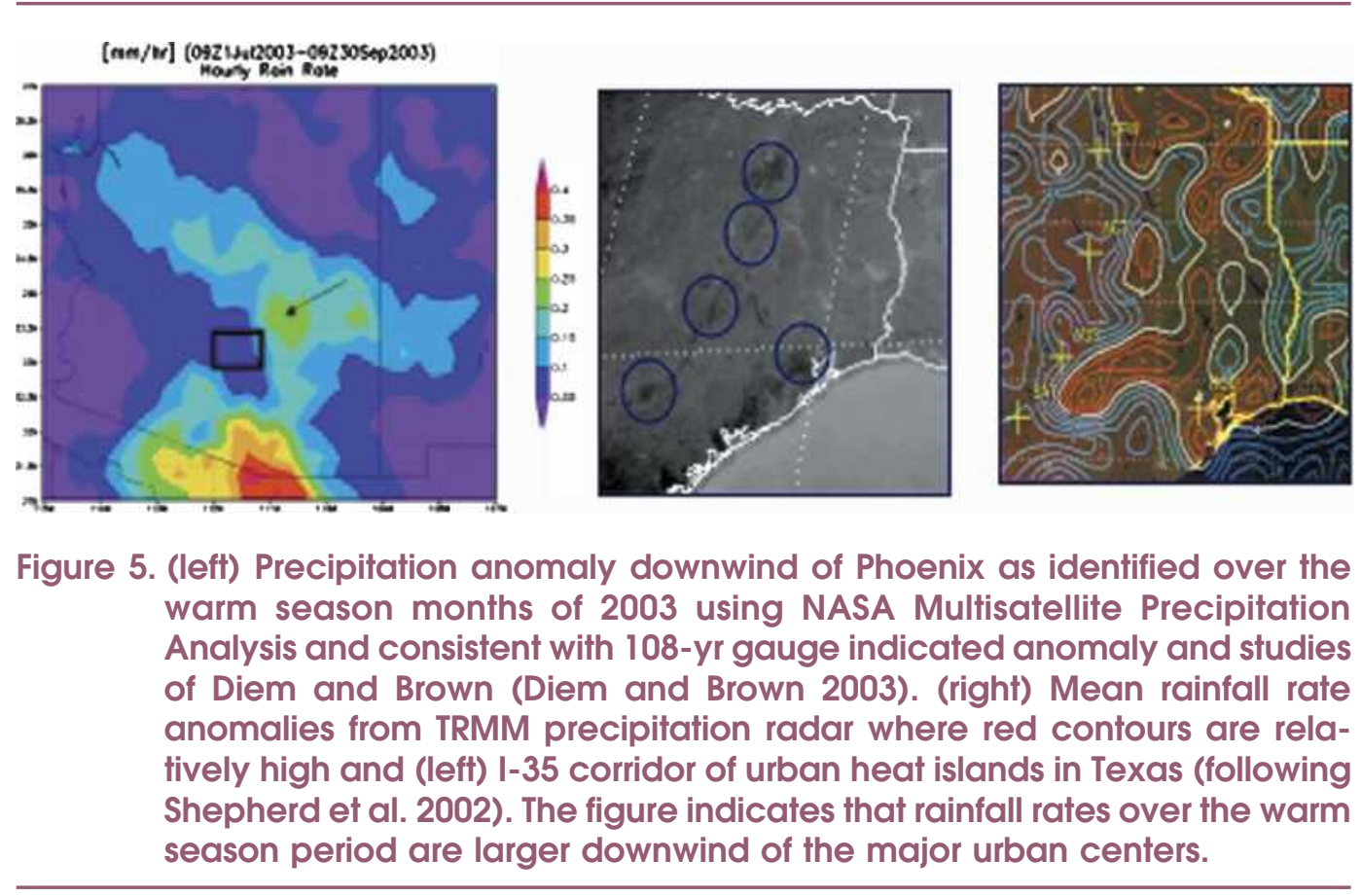

boundaries east of Phoenix interacted with urban dynamic circulations and possibly moisture from irrigation to produce a preferred convective region during the monsoon period.

Dixon and Mote (Dixon and Mote 2003) recently investigated the patterns and causes of Atlanta, Georgia's UHI-initiated precipitation. They suggested urbanrelated moisture sources might be important for convective processes. Their key result was that UHI-induced precipitation soundings showed much higher dewpoints (as much as $5^{\circ} \mathrm{C}$ ) below $550 \mathrm{hPa}$ than average days. Further, airmass analysis showed that these events were more frequent under the most humid air masses rather than the ones with the greatest UHI intensities. Shepherd et al. (Shepherd et al. 2002) tested the concept of using spaceborne precipitation radar to identify rainfall anomalies downwind of Atlanta; Dallas, Texas; and other cities (Figure 5, right). Their results seemed to illustrate that the spaceborne precipitation radar system could identify anomalously high rainfall rates downwind of major cities. To validate the satellite observations, Shepherd and colleagues carried out the 2004 Studies of Precipitation Anomalies from Widespread Urban Land Use (SPRAWL) discussed in Shepherd et al. (Shepherd et al. 2004). The goal of SPRAWL was to obtain a database of urban-induced thunderstorms and associated mesoscale and synoptic conditions. Such cases are now being analyzed and simulated using coupled atmosphere-land surface models. Bornstein and Lin (Bornstein and Lin 2000) used data from Project ATLANTA's 27 mesonet sites and eight National Weather Service sites to investigate interactions of the Atlanta UHI, its convergence zone, and convective storm initiation. They found that UHIinduced convergence could explain convective initiation in several storms observed during the summer of 1996. The first sequence in Movie 2 illustrates how thermal imagery taken over Atlanta (see Quattrochi et al. 1998 for more detailed 


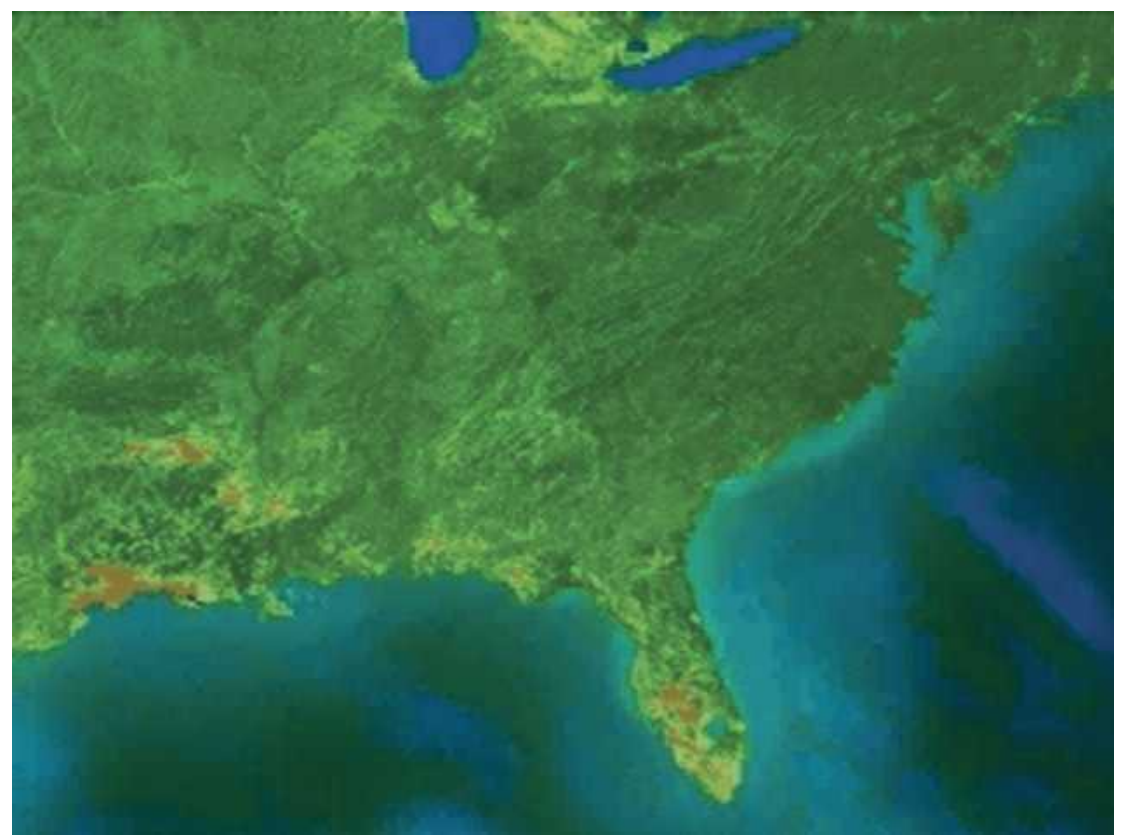

Movie 2. A quick-time movie illustrating the Atlanta, GA, urban heat island using airborne thermal measurements (Quattrochi et al. 1998), growth of the Atlanta metropolitan area using Landsat, and the development of an urban-induced thunderstorm (courtesy of NASA Scientific Visualization Studio).

See the online version of this paper to view animation.

information) is able detect the thermal signature associated with the Atlanta UHI. The second sequence illustrates the growth of Atlanta's metropolitan area over the last three decades using Landsat data. The final sequence in the animation is an enhanced Geostationary Operational Environmental Satellite (GOES) thermal image that clearly shows a thunderstorm (green and red contours representing cloudtop temperature) develop over the metropolitan Atlanta area and drift downwind.

There is increasing evidence that large coastal cities, like Tokyo, Japan, and Houston, Texas, can influence weather through complex urban land use-weatherclimate feedbacks. An engineering study by Bouvette et al. (Bouvette et al. 1982) presented statistical evidence from four Houston area rainfall-recording stations that the 24-h 100-yr storm depth had increased by $15 \%$ in suburban areas when compared to the 24-h 100-yr storm depth published in 1961 by the National Weather Service. They speculated that the change was linked to heavy urban development in Houston, which covers an area of $937 \mathrm{~km}^{2}$. Burian and Shepherd (Burian and Shepherd 2005) used a dense rain gauge network to show statistically significant enhancement to percent occurrence of rainfall in the Houston area. They also showed that the diurnal cycle of rainfall in Houston has also shifted from preurban to posturban time periods. Shepherd and Burian (Shepherd and Burian 2003) used spaceborne radar-estimated rainfall rates and ground-based gauge data to identify warm season, city, and downwind anomalies in precipitation for a major 
Earth Interactions • Volume 9 (2005) • Paper No. 12 • Page 12

coastal city. They hypothesized that dynamic processes related to the urban heat island and enhanced mechanical turbulence in cities interacting with the sea-bay breeze produce a preferred region for convective development in the metropolitan Houston area and regions downwind. Orville et al. (Orville et al. 2001) analyzed 12 yr (1989-2000) of ground-based lightning data for the Houston area. They found that the highest annual and summer flash densities were over and downwind (e.g., northeast-east) of the Houston area. A review of Tokyo's urban-coastal impacts on mesoscale-convective circulations can be found in Kusaka et al. (Kusaka et al. 2000) and Ohashi and Kida (Ohashi and Kida 2002).

Though the literature continues to indicate that the signature of the urban environments may be resolvable in rainfall patterns over and downwind of metropolitan areas, skeptics remain. In a comprehensive review of the subject, Lowry (Lowry 1998) discussed several potential problems with methodology and inferences used in many historical studies of urban-induced precipitation. Lowry recommended that future studies on the subject should have at least the following characteristics.

1) Designed experiments - especially legitimate controls, and where appropriate, stratification schemes-in which explicitly stated hypotheses are tested by means of standard statistical methods.

2) Replication of the experiments in several urban areas [note that the recent emergence of satellite-based precipitation measurement (see Shepherd and Burian 2003) offers a possible resource for achieving this recommendation more efficiently].

3) Use of spatially small, and temporally short, experimental units reflecting the discontinuous nature of precipitating systems.

4) Disaggregation of standard climatic data to increase sample size and avoid merging effects between dissimilar synoptic weather systems.

Additionally, Tayanç et al. (Tayanç et al. 1997) found no evidence of urban effects on precipitation in their study of four large cities in Turkey. Similarly, Robaa (Robaa 2003) suggested in an analysis of Cairo, Egypt, that an inverse relationship existed between the degree of urbanization and rainfall. Such uncertainties illustrate why more observational and modeling research is needed in this area (Dabberdt et al. 2000).

\section{A synopsis of recent modeling efforts}

Numerical modeling efforts are particularly important resources because they enable controlled experiments to characterize the physical processes involved in urban precipitation processes. Surprisingly, a relatively few number of numerical model studies exists in the literature. In part, this is likely due to several factors: 1) poor or nonexistent representation of urban surface parameters, 2) oversimplified or inadequate representation of wet microphysical processes, 3) lack of ability to represent aerosol fields in models, 4) a relative downturn in urban-precipitation research (and funding) in the decade or so following the METROMEX era, and 5) limitations in computing capabilities for fully coupled atmosphere-land modeling systems with explicit microphysical, dynamical, aerosol, and land surface processes. As discussed earlier, simulations by Vukovich and Dunn (Vukovich and Dunn1978) and Hjemfelt (Hjemfelt 1982) suggested that UHI intensity, increased 
urban surface roughness, or urban boundary layer instability enhanced convection. Yoshikado (Yoshikado 1994) used a 2D model to simulate the interactions between a sea-breeze circulation and a heat island circulation in Japan. Kusaka et al. (Kusaka et al. 2000) and Ohashi and Kida (Ohashi and Kida 2002) used 3D models to conduct similar sea-breeze-heat island studies. Thielen et al. (Thielen et al. 2000) used a two-dimensional model to show that surface parameters, especially sensible heat flux, affected the development of precipitation over Paris, France. They showed in numerical simulations that when UHIs are weak, surface sensible heat fluxes, convergence, and buoyancy variations that influence rainfall development are most effective at a distance from the central heat source. Baik et al. (Baik et al. 2001) also used a 2D mesoscale model to understand how atmospheric heating related to UHIs affected dry and moist convection. They showed that when a heat island is present, two regime flows are established. One exhibits a stationary gravity wave near the heating region and the other is characterized by stationary gravity waves near the heating source and an updraft cell downstream from the heating source. These modeling results offer some insight into why there are frequent observations of downwind (relative to the city) maxima in precipitation or convection.

Craig and Bornstein (Craig and Bornstein 2002) reported on 3D mesoscale simulations that showed how the UHI induces convergence and convection. Figure 6 , provided by R. Bornstein (2003, personal communication), illustrates that positive vertical velocities, representing an urban-induced convective event, develop on the eastern edge of Atlanta in this mesoscale model simulation. The vertical velocity maximum was associated with a confirmed thunderstorm and region of maximum surface convergence for this case day. Rozoff et al. (Rozoff et al. 2003), using a storm-resolving model, examined a 1999 storm case in St. Louis to ascertain the role of the urban surface convergence mechanisms on initiating deep, moist convection. They found that surface convergence on the leeward side of the urban heat island plays a key role in initiating convection downwind of the city (Figure 7). Adegoke and Gallo (Adegoke and Gallo 2004) used a cloud-mesoscale modeling system coupled to a land surface boundary condition defined by 1992 Landsat data and 1900 land-cover and land-use data for Washington, D.C. They found a significant increase in surface sensible heat flux and convective precipitation from 1900 to 1992 in their simulation for the month of July. Molders and Olson (Molders and Olson 2004) found evidence of enhanced precipitation over and downwind of high latitude cities like Fairbanks, Alaska. Their mesoscale model simulations indicated that urban land use, aerosols, and moisture sources had statistically significant impacts on downwind precipitation with $95 \%$ confidence.

Previous modeling studies yielded valuable insight but with the exception of Rozoff et al. (Rozoff et al. 2003), the land surface representation was simple or nonexistent. Satellite-derived surface albedo from the National Aeronautic and Space Administration's (NASA's) Moderate Resolution Imaging Spectroradiometer (MODIS) instrument (aboard the Terra spacecraft) for Houston, Texas, indicates that urban landscapes are far from homogeneous and simple (Figure 8). Also, many of these studies did not specifically focus on the linkages of the forcing mechanisms to precipitation processes and often used minimal or simple cloud microphysical parameterizations. Recent modeling results by the author have em- 
Earth Interactions - Volume 9 (2005) - Paper No. 12 • Page 14

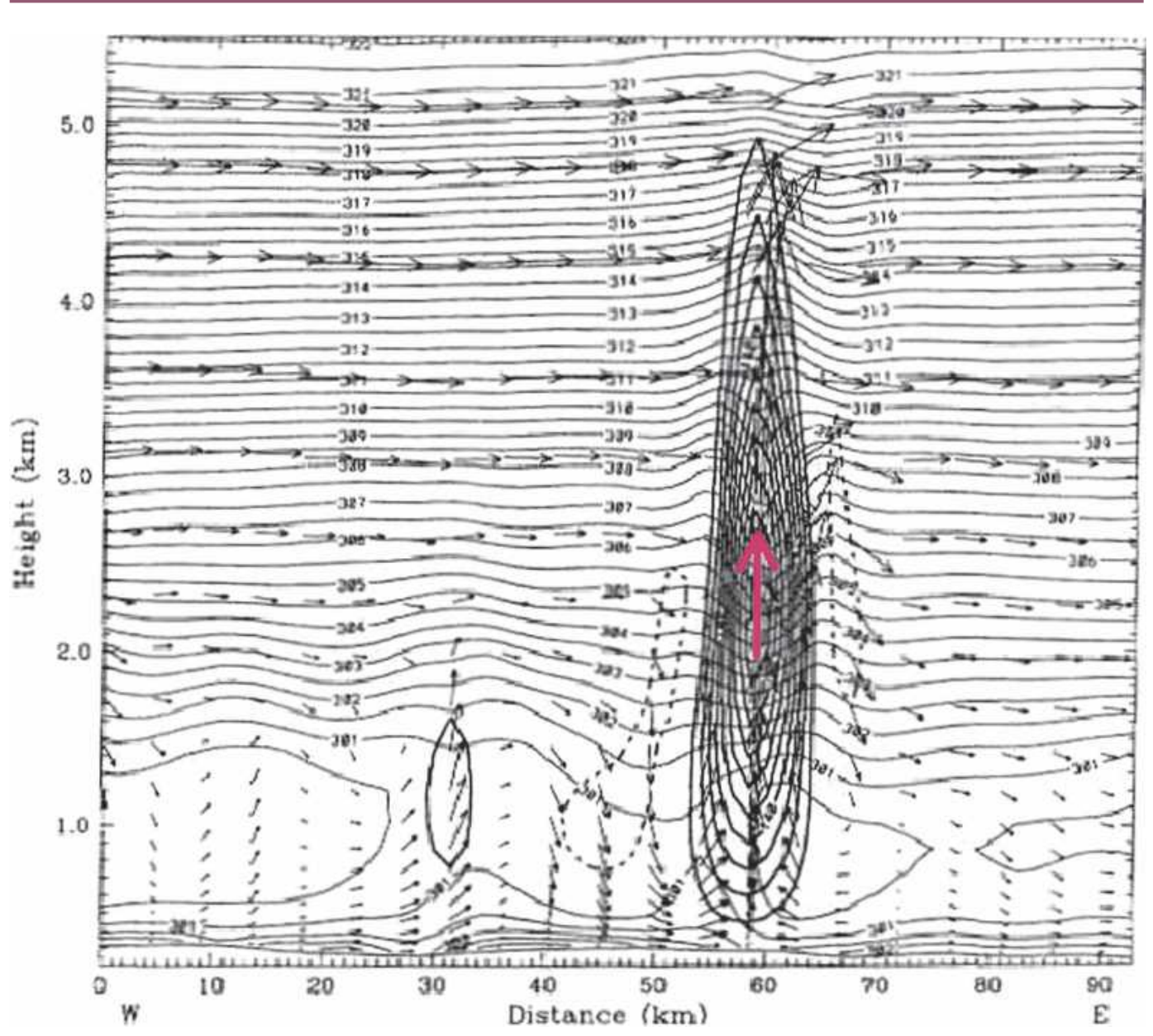

Figure 6. (right) A model cross section through an updraft of an urban-induced storm on the edge of Atlanta (e.g., cityscape is between roughly 30 and $60 \mathrm{~km}$ ). The plot depicts wind flow (arrows), vertical velocity (dark contours), and potential temperature (light contours) (figure courtesy of R. Bornstein, San Jose State University).

ployed a modified version of the fifth-generation Pennsylvania State UniversityNational Center for Atmospheric Research Mesoscale Model (Grell et al. 1994) coupled to the NOAH [National Centers for Environmental Prediction (NCEP) Oregon State University (Department of Atmospheric Sciences) Air Force (AFWA and AFRL) Hydrologic Research Laboratory NWS] land surface model and NASA Goddard Parameterization for Land-Atmosphere-Cloud Exchange (PLACE) model of Wetzel and Boone (Wetzel and Boone 1995). This coupled system also utilizes a sophisticated three-class ice microphysics scheme developed by Tao and Simpson (Tao and Simpson 1993). Figure 9 (left) illustrates the 300-m wind field (vectors), surface fluxes (warm to cool colors), cloud water (purple isosurfaces), and rainwater (yellow isosurfaces) for a case near Houston. On this day (25-26 July 2001) weak large-scale forcing was in place and mesoscale forcing (e.g., sea breeze, urban circulation) was dominant. In the simulation on the 
(a) 1500 UTC

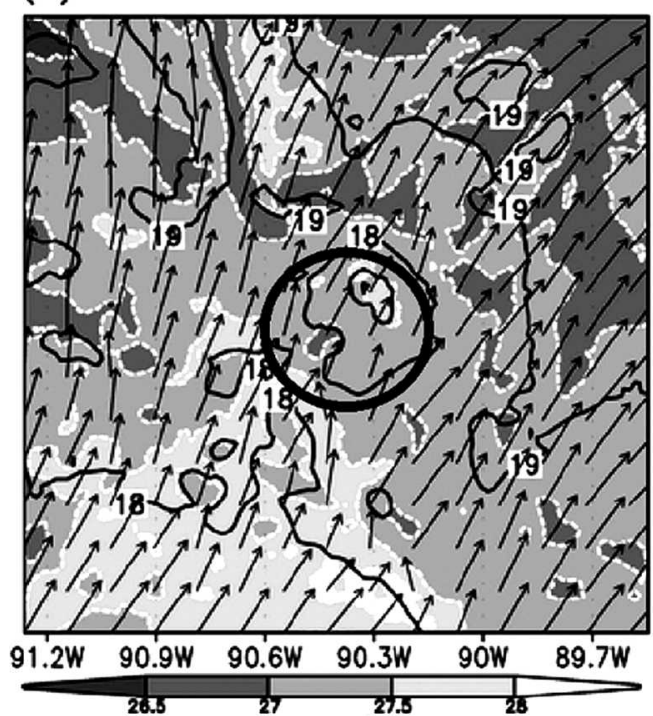

(c) 1700 UTC $\overrightarrow{3}$

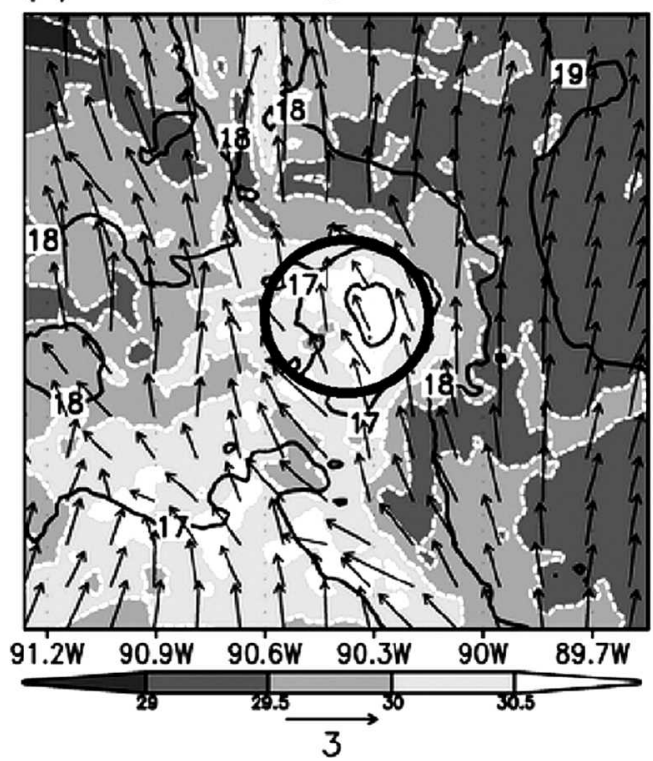

(b) 1600 UTC

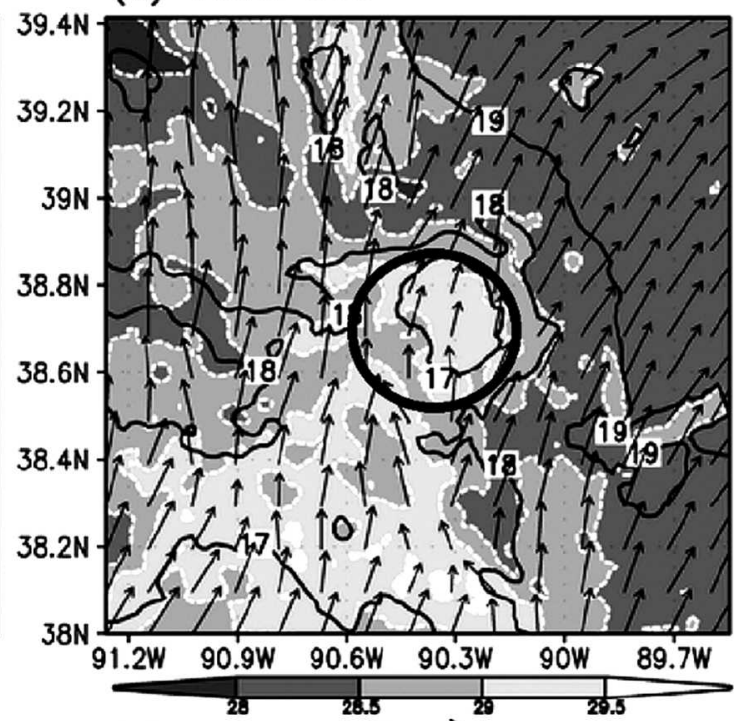

(d) 1800 UTC 3

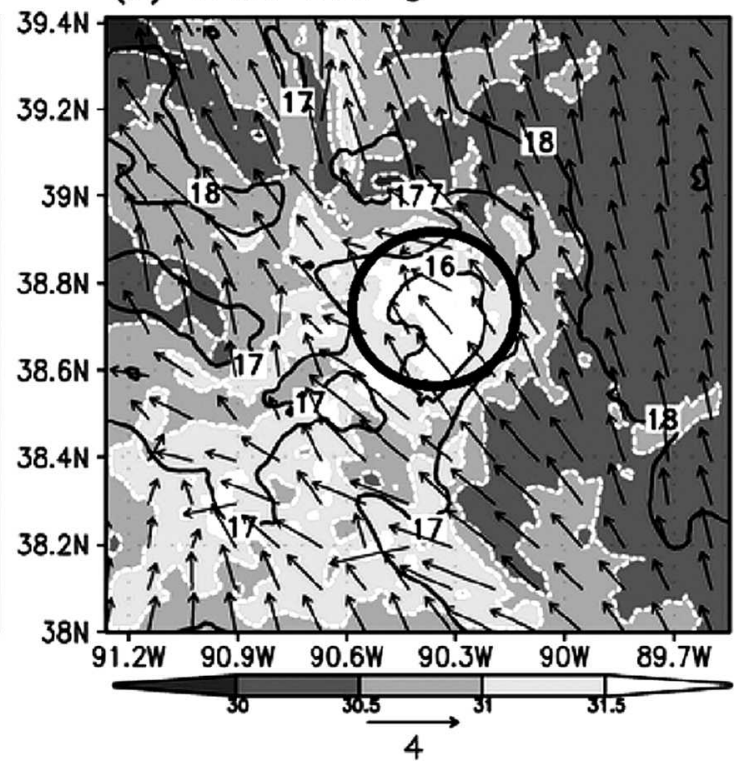

Figure 7. Evolution of urban heat island, moisture, and winds at 48-m level in Colorado State RAMS model simulation on 8 Jun 1999. Temperature $\left({ }^{\circ} \mathrm{C}\right)$ is shaded. Mixing ratio $\left(\mathrm{g} \mathrm{kg}^{-1}\right)$ is contoured. Wind vectors $\left(\mathrm{m} \mathrm{s}^{-1}\right)$ are plotted. There is evidence of moist convergence in the urban environment (following Rozoff et al. 2003). The circle is the approximate location of St. Louis, MO.

right, an urban surface was included in MM5-PLACE by modifying albedo, surface emissivity, roughness length, and vegetation parameters in the land classification. It is evident that the URBAN run produces convection that the NOURBAN run does not feature. It is also evident that urban Houston creates a convergent zone that interacts with the sea-breeze circulation. Radar observations for the 


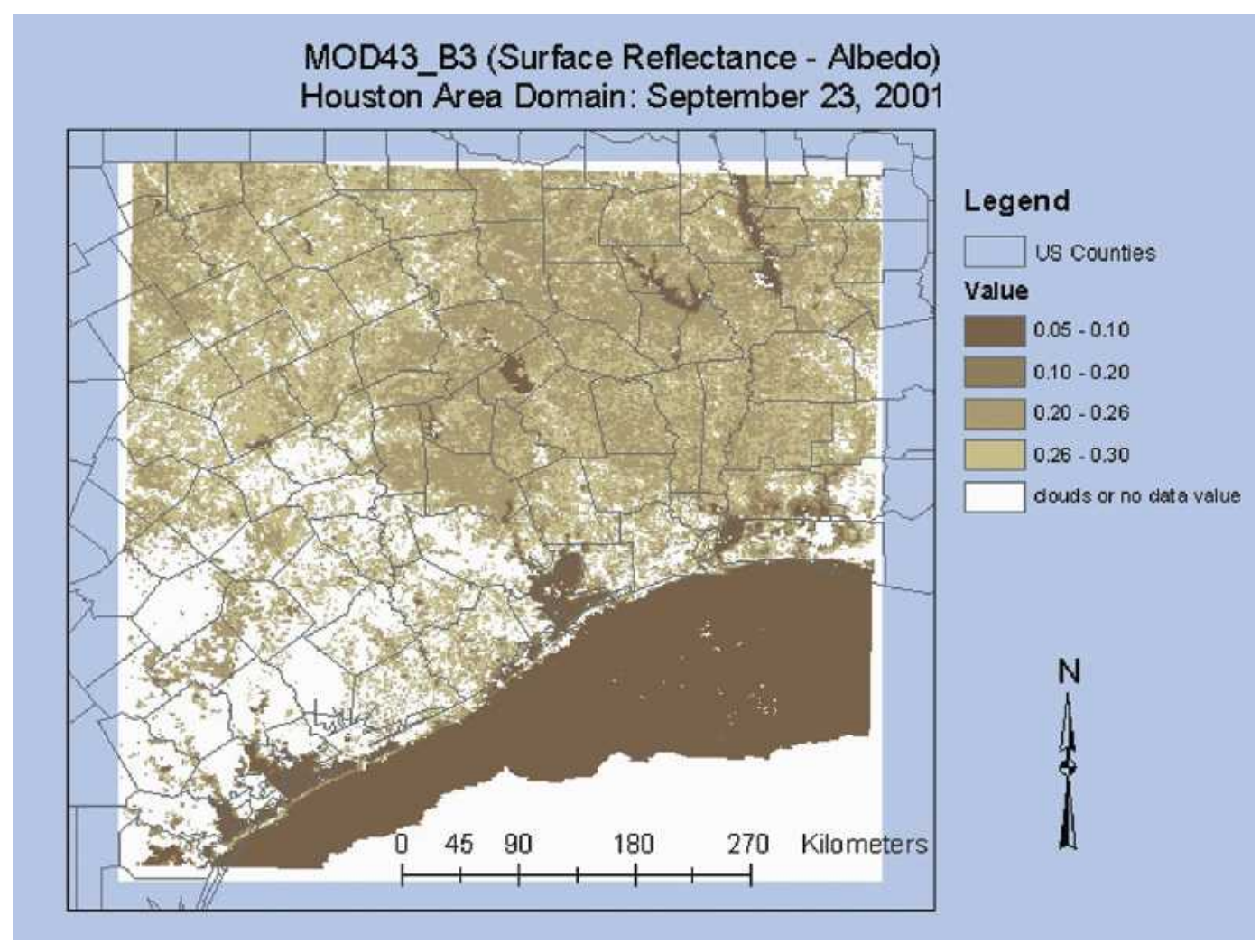

Figure 8. Satellite-derived measurement of surface albedo from NASA's MODIS instrument (aboard the Terra satellite) for Houston, TX. NASA MODIS image is courtesy of M. Jin at University of Maryland.

day confirmed that heavier rainfall was observed over the city of Houston and just to the north of the city. A cross section for this case day (Figure 10) also indicates how the boundary layer (represented in as lines of equivalent potential temperature) responds in the URBAN and NOURBAN case. The URBAN boundary layer is deeper and includes vertical velocity features (red contours). Future efforts will require even explicit representations of urban land surface heterogeneity, urban canopy dynamics and physics, and atmospheric dynamic and moist processes.

\section{The urban dynamics-aerosol debate}

The majority of aforementioned studies focused on dynamic forcing mechanisms related to the urban land use or change and did not address the potential role of aerosols. Ramanathan et al. (Ramanathan et al. 2001) reported that urban areas reduce rainfall due to cloud microphysics. Rosenfeld (Rosenfeld 1999; Rosenfeld 2000) has recently observed that urban and industrial aerosols may actually suppress rain and snow by providing large concentrations of small cloud condensation nuclei, which lead to large quantities of small cloud droplets (Figure 11). He further explained that the clouds must grow to greater depth and colder cloud-top temperatures for the onset of precipitation. This requirement means that precipitation would be suppressed when aerosols are ingested into relatively shallow and 


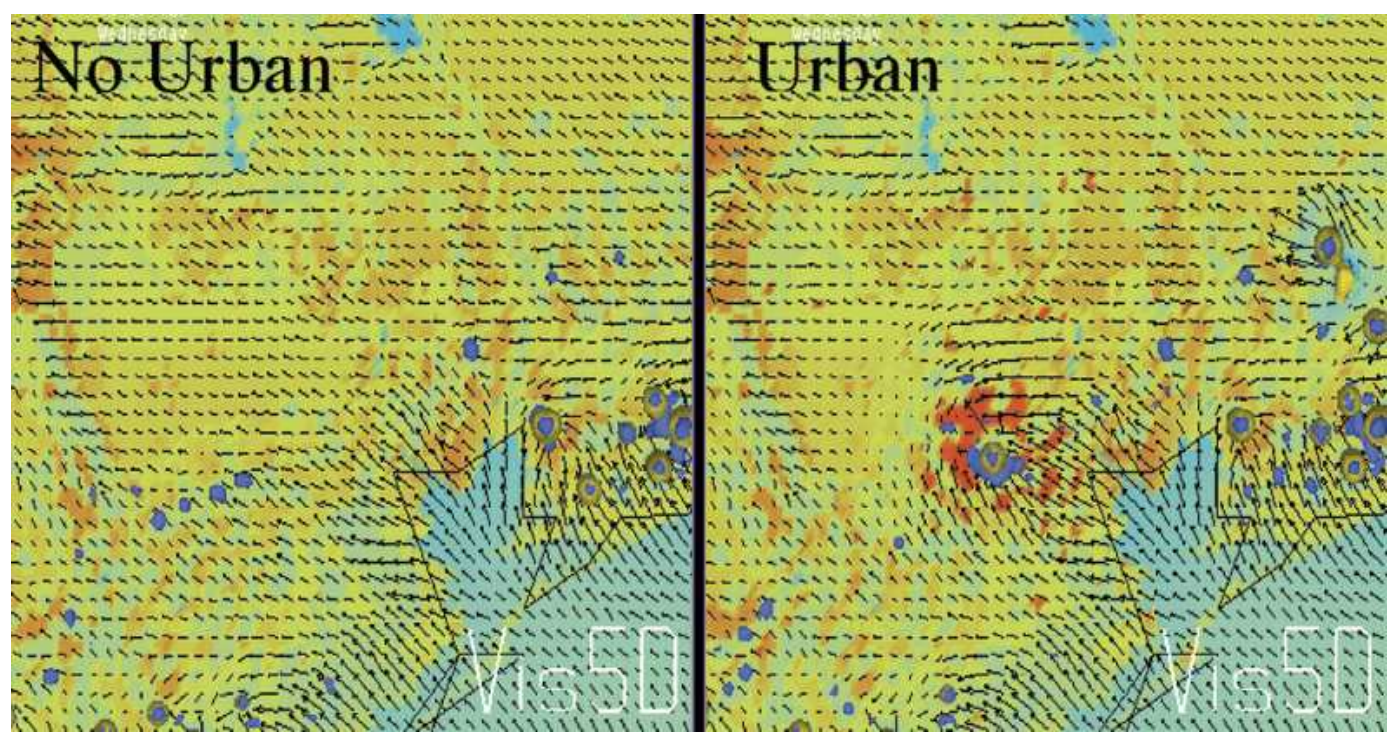

Figure 9. MM5-NOAH simulation of 25-26 Jul 2001 case day for Houston. Black arrows represent wind vectors at $300 \mathrm{~m}$. Warm to cool colors represent ground temperature. Purple isosurfaces represent cloud water. Yellow isosurfaces represent rainwater. The time for this particular plot is 1740 UTC.

short-lived clouds. Others have theorized that these processes could lead to enhanced lightning activity because of changes in the vertical distribution of the liquid and frozen hydrometeors (Steiger et al. 2002; Orville et al. 2001).

Recently, Borys et al. (Borys et al. 2000; Borys et al. 2003) provided evidence that pollution can suppress precipitation in winter orographic clouds. Their analysis shows that pollution increases the concentration of $\mathrm{CCN}$ and of cloud drops, leading to the formation of smaller cloud drops. The reduced drop size leads to a less efficient riming process, to smaller ice crystals, smaller fall velocities, and smaller amounts of snowfall. This observation concurs with a very recent study by Givati and Rosenfeld (Givati and Rosenfeld 2004) who analyzed precipitation record in regions downwind from pollution centers and compared them to regions unaffected by them. Two different geographical areas were chosen for this study, California and Israel. The topography in both regions is similar, although the mountains in Israel are much lower than the Sierra Nevada. The statistical results in both locations show that on the upslope of the mountain and the mountaintop, both downwind of the pollution region, precipitation is reduced by about $20 \%$ and $7 \%$ respectively. This decrease is due to increase in droplet concentrations and the decrease in droplet size. Farther downwind and on the lee side of the mountain, the amount of precipitation actually increased by about $14 \%$. The authors explain this increase by the fact that the smaller cloud particles need a longer time to grow, allowing the winds aloft to carry them over the mountaintop. However, the integrated rainfall amount over the whole track of the clouds is reduced.

However, recent evidence has been presented in Andreae et al. (2004) that dirty or smoky clouds might invigorate convective or precipitation processes. Dirty clouds over Amazonia remained in the atmosphere for a long time due to the lack 


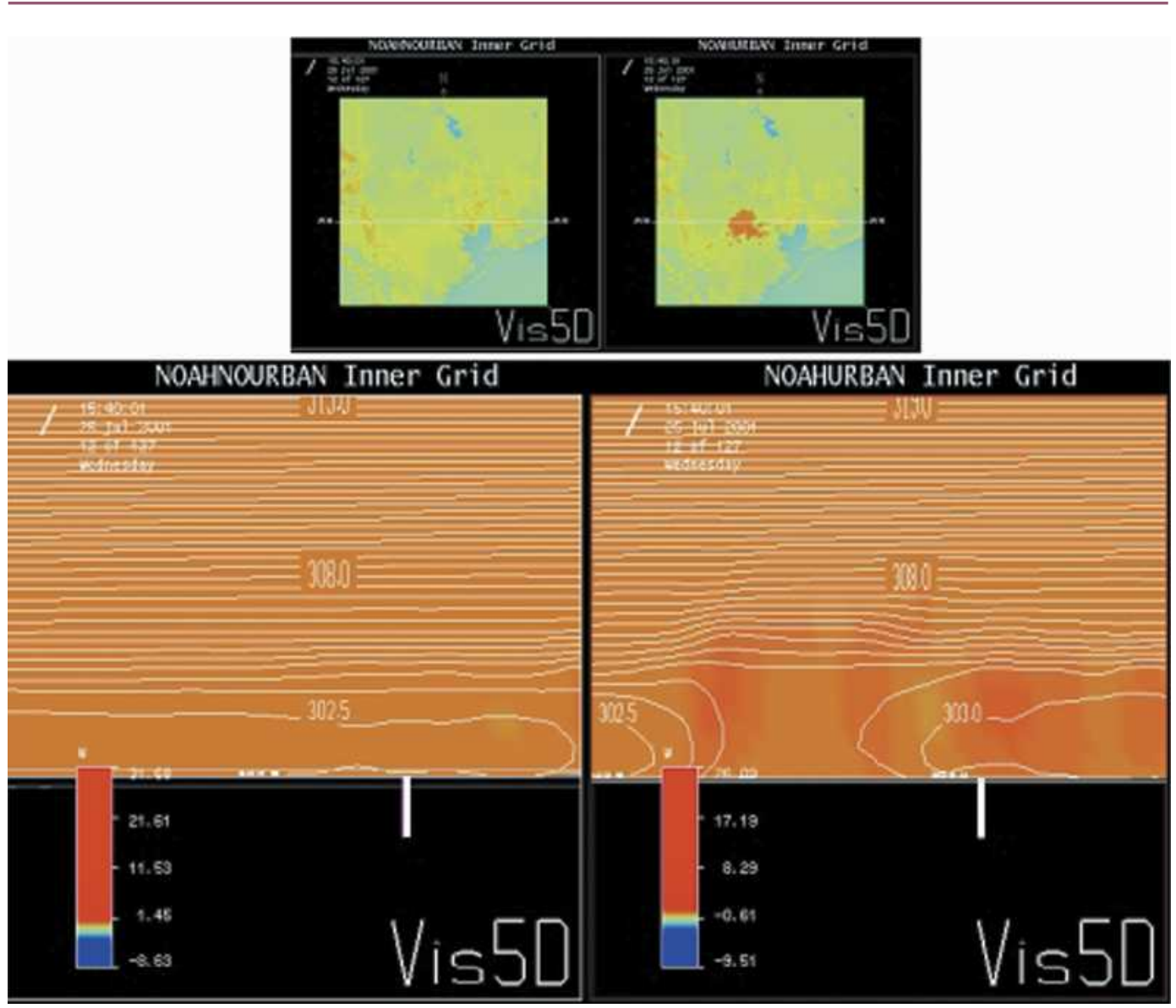

Figure 10. Cross section of equivalent potential temperature $(K)$ and vertical velocity $\left(\mathrm{m} \mathrm{s}^{-1}\right)$ at 1540 UTC (just prior to first convective clouds).

of rain. They reported that the high concentrations of cloud drops reduce the efficiency for growth by collection. Therefore, they continue to grow by condensation and reach higher altitudes and lower temperatures where ice can form. Since these clouds are deeper they could produce lightning, hail, and heavy rain; D. Rosenfeld (2003, personal communication) has suggested that this process may occur in urban polluted clouds. Rosenfeld also argued that aerosols suppress the onset of precipitation in warm base convective clouds that develop in moist tropical air masses (see Figure 11). In numerical simulations with explicit microphysical processes, Rosenfeld and colleagues found that delay of warm rain onset results in delayed downdraft formation. This process allows for a more invigorated updraft that produces deeper and stronger convection. Professor Rosenfeld proposed that this initial suppressive process is actually an additional enhancement mechanism in addition to UHI-related dynamics. Furthermore, he argued that the transition from warm to ice phase precipitation processes advects more cloud water to the supercooled levels higher in the cloud. The additional cloud water and strong updraft prime the cloud for enhanced electrical activity as observed recently in Houston by Orville et al. (Orville et al. 2001) and in Louisiana by Steiger and 
Earth Interactions • Volume 9 (2005) • Paper No. 12 • Page 19

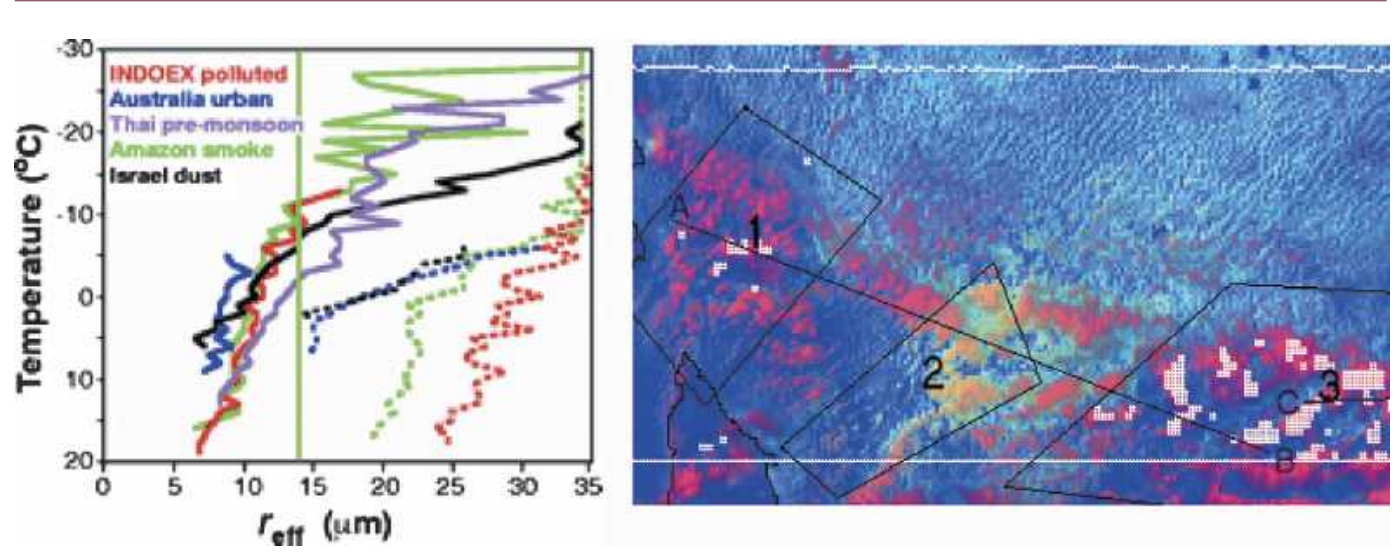

Figure 11. (left) Satellite-retrieved median effective radius of particles near the top of deep convective clouds at various stages of their vertical development, as a function of the cloud-top temperature, which serves as a surrogate for cloud-top height. The effective radius is the ratio of the integral of the third moment $(13)$ of the radius, weighted with the number concentration at that radius, to its second moment (12). This is shown for clouds forming in polluted (solid lines) and pristine air (broken lines). The red lines denoted by "INDOEX polluted" are for data along a track that runs from southwestern India into the Indian Ocean. The blue lines are for tracks over urban southeastern Australia. Violet lines are for Thailand premonsoon clouds with suppressed coalescence. Green lines are for biomass smoke over the Amazon. Black lines are for desert dust over Israel. The vertical green line denotes the 14- $\mu \mathrm{m}$ precipitation threshold radius (following Ramanathan et al. 2001). (right) TRMM satellite data near Australia showing rainfall suppression by biomass burning and smoke (yellow). Area 3 is characterized by no aerosol contamination and rainfall (white) (following Rosenfeld 2000).

Orville (Steiger and Orville 2003). The general conclusion is that aerosols can have large impacts on the precipitation processes in clouds and can enhance or suppress precipitation depending on cloud type, seasonality, climate regime, or orographic profile of the urban area. An important conclusion from recent work is that there is evidence of convergence in both the UHI dynamics arguments and aerosol-microphysics arguments for precipitation variability in urban environments.

In contrast to discussions about urban aerosols suppressing rainfall, Diem and Brown (Diem and Brown 2003) partially attributed downwind precipitation enhancement in Phoenix to increased pollution-derived $\mathrm{CCN}$, although they acknowledged that increased humidity from human irrigation projects and urbaninduced surface convergence were likely the dominant factors. Molders and Olson (Molders and Olson 2004) modified the explicit moisture scheme of Schultz (Schultz 1995) to include aerosol effects. Urban aerosols' release was represented by adding $2 \times 10^{9} \mathrm{~m}^{3} \mathrm{CCN} / \mathrm{IN}$ (ice nuclei) to the number of aerosols and setting the radius distribution spectrum equal to 0.1 in the first six layers over Fairbanks. In this scenario, more but smaller aerosols are assumed. Their results showed that a statistically significant enhancement in precipitation occurred downwind of Fair- 
Earth Interactions - Volume 9 (2005) - Paper No. 12 • Page 20

banks when additional aerosols were released in their mesoscale-model simulations. They attributed the enhancement to shifts in the cloud microphysical processes. However, their study also found detectable changes in precipitation when urban land surfaces and moisture were altered. The uncertainty in the role of urban aerosols on precipitation is clearly evident.

\section{Concluding statements on what is needed to address urban-induced precipitation questions}

As concern grows about the impact of anthropogenic and natural processes on climate change, water cycle accelerations, and precipitation variability, it is important to place urban processes into the context of regional and global climate system processes. The debate has generally shifted from "How do urban areas affect precipitation?" to characterizing how and why the urban environment affects rainfall. To fully address the relationships and interactions between the urban environment and precipitation, several things are required.

\subsection{New observing systems must be developed to monitor and track anthropogenic and natural aerosols, land-cover/ land-use changes, cloud microphysics, and precipitation processes}

More specifically, the following observations systems are requirements that would be valuable.

\subsubsection{Land use}

- A continuation of Landsat quality data records and inventories of land-use and land-cover change or extension of Landsat-type measurements to geosynchronous orbit.

- Improved observations and representation of urban canopies and buildings and the possible use of aircraft- and satellite-based synthetic aperture or lidar technology (Burian et al. 2004b) discuss recent applications of lidar and synthetic aperture radar for assessing urban canopies. Burian et al. (Burian et al. 2003) also provide a current synopsis of many currently available urban geo-database systems.

\subsubsection{Aerosols}

- Systematic aircraft measurements of aerosol concentration, chemistry, and cloud properties with simultaneous measurements of the precipitation rates on the ground.

- More accurate assessment from satellites of the aerosol column concentration and properties by measurements of the full properties of the reflected sunlight are needed. Emerging satellite systems like Aura, CALIPSO, PARASOL, and other systems (more information online at http://science. nasa.gov) will provide some capabilities in these areas. 
Earth Interactions - Volume 9 (2005) - Paper No. 12 • Page 21

\subsubsection{Clouds}

- A full spectrum of measurements of cloud droplet microphysics and distributions would be useful.

- Measurements of the vertical profiles of cloud microphysics by profiling aircraft instruments and from satellites. Emerging systems like CloudSat and CALIPSO (more information online at http://science.nasa.gov).

\subsubsection{Precipitation}

- Continuous measurements from space of the precipitation patterns in missions coordinated with detailed clouds and aerosol measurements.

- More frequent and accurate space-based measurements of global precipitation with error statistics [e.g., Global Precipitation Measurement (GPM)era].

- Dual-frequency, space-based radar measurements (e.g., GPM) to assess vertical profiles of precipitation relative to cloud and aerosol profiles and raindrop microphysical parameters (e.g., DSD).

\subsection{Modeling systems that explicitly resolve aerosols, cloud microphysics, complex land surfaces, and precipitation evolution so that a more conclusive understanding of the feedbacks and interactions can be attained}

Ongoing work by Khain et al. (Khain et al. 2004) is advancing the use of spectral (bin) microphysics to simulate aerosols in cloud-mesoscale modeling systems. Molders and Olson (Molders and Olson 2004) also demonstrated methodologies for introducing aerosols into mesoscale modeling systems. Research efforts in NASA Goddard's cloud modeling group have also recently implemented the Khain microphysics scheme into its cloud modeling system. Additionally, high performance land surface modeling and data assimilation systems like the NASA Land Information System (Peters-Lidard et al. 2004) embody the need for improved representation of complex and heterogeneous land surfaces. The obvious next steps involve coupling these land surface, mesoscale, and aerosolmicrophysics schemes.

\subsection{Implementation of urban parameterizations at the local scale to resolve urban canyon, dynamics, and flux processes, particularly in terms of roughness, surface cover properties, low-level moisture associated with irrigation, and aerosols}

Though it is not clear what role local urban canopy scale dynamics play in largerscale precipitation process, it is imperative to enable a capability to test urban canopy dynamics (UCD) impacts. A recent paper by Dupont et al. (Dupont et al. 2004) identified the importance of complex surface characterization and urban canopies on predicting several meteorological fields, but precipitation was not included. Kusaka and Kimura (Kusaka and Kimura 2004) embedded an urban canopy model in a mesoscale model and demonstrated that canyon structure was as significant as anthropogenic heating in producing a nocturnal heat island. Yet, 
Earth Interactions - Volume 9 (2005) - Paper No. 12 • Page 22

this paper did not focus on wet microphysical (e.g., cloud or precipitation) processes either. Earlier, we also discussed a paper by Diem and Brown (Diem and Brown 2003) that hinted at possible influences of irrigation-related moisture; therefore, modeling systems must address this factor more thoroughly in the future.

\subsection{Field studies to validate satellite observations and modeling simulations of urban precipitation processes and to extend basic understanding of the processes involved}

The SPRAWL and Project Atlanta experiments reported in Shepherd et al. (Shepherd et al. 2004) and Quattrochi et al. (Quattrochi et al. 1998) are the types of field experiments required to isolate specific synoptic flow regimes, mesoscale conditions, and precipitation cases. Field studies enable detailed interrogation of the underlying physical processes for specific cases and candidate case days for modeling studies. It is important that efforts like the Houston Environmental Aerosol Thunderstorm Project (HEAT) are funded and implemented where possible (online at http://www.met.tamu.edu/ciams/heat/).

\subsection{Climate modeling systems that adequately characterize the urban environment are required to understand the aggregate roles of global urban surfaces on the Earth's climate system, particularly the precipitation component of the water cycle under different growth and climate change scenarios}

As the evidence that urban areas impact precipitation mounts, the climate modeling community must begin to represent urban land surface and aerosol processes to better understand the aggregate influences of built-up land and urban aerosols on short- and long-term climate change. An article discussing such issues is forthcoming (Jin and Shepherd 2005: manuscript submitted to Bull. Amer. Meteor. Soc.). Additionally, the author has contributed text to the next Intergovernmental Panel on Climate Change (IPCC) assessment report, which will be published in a few years.

\subsection{Assessment of the impact of urban-induced rainfall on societal applications}

For example, Bertness (Bertness 1980) provided an overview of rain-related impacts on transportation and energy services in the Chicago area. Changnon and Westcott (Changnon and Westcott 2002) found that operations of a dense rain gauge network in the Chicago area since 1989 provided data to assess the temporal and spatial distributions of heavy rainstorms. The 12-yr average was 4.4 storms per year, $40 \%$ more than in the 1948-80 period, reflecting an ongoing Midwestern increase in heavy rains. The total rainfall from the 53 heavy rainstorms maximized over the city, reflecting previous observations that the influence of the city and Lake Michigan on the atmosphere causes an increase in heavy rains. Impacts from the record high number of eight storms in 2001 revealed that efforts to control flooding, including the Deep Tunnel system, had reduced street and basement 
flooding in the moderate intensity storms, but the two most intense storms, each with $100 \mathrm{yr}$ rainfall values, led to excessive flooding and a need to release flood waters into Lake Michigan. Burian et al. (Burian et al. 2004a) discuss the implications of urban-induced precipitation on the design of urban drainage systems. Such examples of science knowledge transfer in the civil engineering, water resource, and planning communities must be mirrored in areas related to precision agriculture, transportation systems weather forecasting, and other applications that may be impacted by more frequent or intense urban storms.

Even within the recommendations, it is apparent that some investigators are starting to address several of these issues. These efforts will certainly move the science understanding forward. Additionally, knowledge of how urban environments impact precipitation will undoubtedly have implications for how urban areas are represented in future generations of weather and climate models, how urban planners and water resource managers plan cities, how agricultural activities are carried out, and numerous other societal benefit applications.

Acknowledgments. The authors acknowledge the support of NASA's Precipitation Measurement Missions program, managed by Dr. Ramesh Kakar, and the New Investigator Program, managed by Dr. Ming-Ying Wei. We also thank Michael Manyin of SSAI, Inc.; Dr. Peter Wetzel (NASA); and the anonymous reviewers of the manuscript.

\section{References}

Adegoke, J. O., and K. P. Gallo, 2004: On the relation between surface spatial heterogeneity and climate prediction: Insights from the integration of fine resolution satellite land information into mesoscale climate models. Preprints, Eighth Symp. on Integrated Observing and Assimilation Systems for Atmosphere, Oceans, and Land Surface, Seattle, WA, Amer. Meteor. Soc., CD-ROM, 1.1.

Andreae, M. O., D. Rosenfeld, P. Artaxo, A. A. Costa, G. P. Frank, K. M. Longo, and M. A. F. Silva-Dias, 2004: Smoking rain clouds over the Amazon. Science, 303, 1337-1341.

Atkinson, B. W., 1968: A preliminary investigation of the possible effect of London's urban area on the distribution of thunder rainfall, 1951-1960. Trans. Inst. Brit. Geogr., 44, 97-118.

Baik, J.-J., Y. H. Kim, and H. Y. Chun, 2001: Dry and moist convection forced by an urban heat island. J. Appl. Meteor., 40, 1462-1475.

Balling, R., and S. Brazel, 1987: Recent changes in Phoenix summertime diurnal precipitation patterns. Theor. Appl. Climatol., 38, 50-54.

Bertness, J., 1980: Rain-related impacts on selected transportation activities and utility services in the Chicago area. J. Appl. Meteor., 19, 545-556.

Bornstein, R., and M. LeRoy, 1990: Urban barrier effects on convective and frontal thunderstorms. Preprints, Conf. on Mesoscale Processes, Boulder, CO, Amer. Meteor. Soc., 25-29.

— and Q. Lin, 2000: Urban heat islands and summertime convective thunderstorms in Atlanta: Three cases studies. Atmos. Environ., 34, 507-516.

Borys, R. D., D. H. Lowenthal, and D. L. Mitchell, 2000: The relationships among cloud microphysics, chemistry and precipitation rate in cold mountain clouds. Atmos. Environ., 34, 2593-2602.

- - - S. A. Cohn, and W. O. J. Brown, 2003: Mountain and radar measurements of anthropogenic aerosol effects on snow growth and snowfall rate. Geophys. Res. Lett., 30, 1538, doi:10.1029/2002GL016855. 


\section{Earth Interactions • Volume 9 (2005) • Paper No. 12 • Page 24}

Bouvette, T., J. L. Lambert, and P. B. Bedient, 1982: Revised rainfall frequency analysis for Houston. J. Hydraul. Div. Proc. Amer. Soc. Civil Eng., 108, 515-528.

Braham, R. R., R. G. Semonin, A. H. Auer, S. A. Changnon Jr., and J. M. Hales, 1981: Summary of urban effects on clouds and rain. METROMEX: A Review and Summary, Meteor. Monogr., No. 40, Amer. Meteor. Soc., 141-152.

Burian, S. J., and J. M. Shepherd, 2005: Effects of urbanization on the diurnal rainfall pattern in Houston: Hydrological processes. Rainfall Hydrol. Proc., 19, 1089-1103.

— , T. N. McPherson, M. J. Brown, G. E. Streit, and H. J. Turin, 2003: Urban environmental modeling and assessment using detailed urban databases. Earth Science in the City: A Reader, G. Heiken, R. Fakundiny, and J. Sutter, Eds., Amer. Geophys. Union, 303-333.

_ J. M. Shepherd, and P. Hooshialsadat, 2004a: Urbanization impacts on Houston rainstorms. Innovative Modeling of Urban Water Systems, W. James, Ed., BPR, 1-22.

— W. Wtetson, W. S. Han, J. K. S. Ching, and D. W. Byun, 2004b: High-resolution dataset of urban canopy parameters for Houston, Texas. Preprints, Fifth Conf. on Urban Environment, Vancouver, BC, Canada, Amer. Meteor. Soc., CD-ROM, 9.3.

Changnon, S. A., 1968: The LaPorte weather anomaly-Fact or fiction? Bull. Amer. Meteor. Soc., 49, 4-11.

_ _ 1979: Rainfall changes in summer caused by St. Louis. Science, 205, 402-404.

_ 1992: Inadvertent weather modification in urban areas: Lessons for global climate change. Bull. Amer. Meteor. Soc., 73, 619-627.

—, 2003: Urban modification of freezing-rain events. J. Appl. Meteor., 42, 863-870.

— impacts, and future implications. J. Amer. Water Res. Assoc., 38, 1467-1475.

— , F. A. Huff, P. T. Schickedanz, and J. L. Vogel, 1977: Weather anomalies and impacts: In summary of METROMEX Vol. I. Illinois State Water Survey Bulletin 62, 260 pp.

— R. G. Semonin, A. H. Auer, R. R. Braham, and J. Hales, 1981: METROMEX: A Review and Summary. Meteor. Monogr., No. 40, Amer. Meteor. Soc., 81 pp.

— R. T. Shealy, and R. W. Scott, 1991: Precipitation changes in fall, winter, and spring caused by St. Louis. J. Appl. Meteor., 30, 126-134.

Climate Change Science Program and Subcommittee on Global Change Research, 2003: Strategic plan for the U.S. Climate Change Science Program. FInal Rep., 221 pp. [Available online at http://climatescience.gov.]

Craig, K., and R. Bornstein, 2002: MM5 simulation of urban induced convective precipitation over Atlanta. Preprints, Fourth Conf. on the Urban Environment, Norfolk, VA, Amer. Meteor. Soc., 5-6.

Dabberdt, W. F., and Coauthors, 2000: Forecast issues in the urban zone: Report of the 10th prospectus development team of the U.S. Weather Research Program. Bull. Amer. Meteor. Soc., 81, 2047-2064.

Dai, A., I. Y. Fung, and A. D. Del Genio, 1997: Surface observed global land precipitation variations during 1900-88. J. Climate, 10, 2943-2962.

Diem, J. E., and D. P. Brown, 2003: Anthropogenic impacts on summer precipitation in central Arizona, U.S.A. Prof. Geogr., 55 (3), 343-355.

Dixon, P. G., and T. L. Mote, 2003: Patterns and causes of Atlanta's urban heat island-initiated precipitation. J. Appl. Meteor., 42, 1273-1284.

Dupont, S., T. Otte, and J. Ching, 2004: Simulation of meteorological fields within and above urban and rural canopies with a mesoscale model. Bound.-Layer Meteor., 113, 111-158.

Elvidge, C. D., C. Milesi, J. B. Dietz, B. T. Tuttle, P. C. Sutton, R. Nemani, and J. E. Vogelmann, 2004: U.S. constructed area approaches the size of Ohio. Eos., Trans. Amer. Geophys. Union, 85, 233. 


\section{Earth Interactions • Volume 9 (2005) • Paper No. 12 • Page 25}

Fujibe, F., 2003: Long-term surface wind changes in the Tokyo Metropolitan area in the afternoon of sunny days in the warm season. J. Meteor. Soc. Japan, 81, 141-149.

— island. J. Meteor. Soc. Japan, 58, 149-152.

Givati, A., and D. Rosenfeld, 2004: Quantifying precipitation suppression due to air pollution. $J$. Appl. Meteor., 43, 1038-1056.

Grell, G. A., J. Dudhia, and D. R. Stauffer, 1994: A description of the fifth-generation Penn State/NCAR Mesoscale Model (MM5). NCAR Tech. Note NCAR/TN-398+STR, 122 pp.

Hjemfelt, M. R., 1982: Numerical simulation of the effects of St. Louis on mesoscale boundary layer airflow and vertical motion: Simulations of urban vs. non-urban effects. J. Appl. Meteor., 21, 1239-1257.

Horton, R. E., 1921: Thunderstorm breeding spots. Mon. Wea. Rev., 49, 193-194.

Huff, F. A., 1986: Urban hydrological review. Bull. Amer. Meteor. Soc., 67, 703-712.

— Louis. J. Appl. Meteor., 11, 823-842.

— region. J. Appl. Meteor., 17, 565-577.

Inoue, T., and F. Kimura, 2004: Urban effects on low-level clouds around the Tokyo metropolitan area on clear summer days. Geophys. Res. Lett., 31, L05103, doi:10.1029/2003GL018908.

Jauregui, E., and E. Romales, 1996: Urban effects on convective precipitation in Mexico City. Atmos. Environ., 30, 3383-3389.

Jin, M., and J. M. Shepherd, 2005: Inclusion of urban landscape in a climate model: How can satellite data help? Bull. Amer. Meteor. Soc., 86, 681-689.

Khain, A., A. Pokrovsky, M. Pinsky, A. Seifert, and V. Phillips, 2004: Simulation of effects of atmospheric aerosols on deep turbulent convective clouds using a spectral microphysics mixed-phase cumulus cloud model. Part I: Model description and possible applications. $J$. Atmos. Sci., 61, 2963-2982.

Kim, Y.-H., and J.-J. Baik, 2002: Maximum urban heat island intensity in Seoul. J. Appl. Meteor., 41, 651-659.

Kusaka, H., and F. Kimura, 2004: Thermal effects of urban canyon structure on the nocturnal heat island: Numerical experiment using a mesoscale model coupled with an urban canopy model. J. Appl. Meteor., 43, 1899-1910.

— - _ - H. Hirakuchi, and M. Mizutori, 2000: The effects of land-use alteration on the sea breeze and daytime heat island in the Tokyo metropolitan area. J. Meteor. Soc. Japan, 78, 405-420.

Landsberg, H. E., 1956: The climate of towns. Man's Role in Changing the Face of the Earth, W. L. Thomas, Ed., University of Chicago Press, 584-606. 1970: Man-made climate changes. Science, 170, 1265-1274.

Loose, T., and R. D. Bornstein, 1977: Observations of mesoscale effects on frontal movement through an urban area. Mon. Wea. Rev., 105, 563-571.

Lowry, W., 1998: Urban effects on precipitation amount. Prog. Phys. Geogr., 22, 477-520.

Molders, N., and M. A. Olson, 2004: Impact of urban effects on precipitation in high latitudes. $J$. Hydrometeor., 5, 409-429.

Ohashi, Y., and H. Kida, 2002: Local circulations developed in the vicinity of both coastal and inland urban areas: Numerical study with a mesoscale atmospheric model. J. Appl. Meteor., 41, 30-45.

Oke, T. R., 1981: Canyon geometry and nocturnal urban heat island: Comparison of scale model and field observations. J. Climatol., 1, 237-254.

— 1987: Boundary Layer Climates. 2d ed. Methuen Co., 435 pp.

Orville, R., and Coauthors, 2001: Enhancement of cloud-to-ground lightning over Houston Texas. Geophys. Res. Lett., 28, 2597-2600. 


\section{Earth Interactions • Volume 9 (2005) • Paper No. 12 • Page 26}

Peters-Lidard, C. D., S. Kumar, Y. Tian, J. L. Eastman, and P. Houser, 2004: Global urban-scale land-atmosphere modeling with the Land Information System, Preprints, Symp. on Planning, Nowcasting, and Forecasting in the Urban Zone, Seattle, WA, CD-ROM, 4.1.

Quattrochi, D., and Coauthors, 1998: Project Atlanta (Atlanta Land use Analysis: Temperature and Air Quality): A study of how urban landscape affects meteorology and air quality through time. Preprints, Second Urban Environment Conf., Albuquerque, NM, Amer. Meteor. Soc., 104-107.

Ramanathan, V., P. J. Crutzen, J. T. Kiehl, and D. Rosenfeld, 2001: Aerosols, climate, and the hydrological cycle. Science, 294, 2119-2124.

Robaa, S. M., 2003: Urban-suburban/rural differences over Greater Cairo, Egypt. Atmosfera, 16 (3), 157-171.

Rosenfeld, D., 1999: TRMM observed first direct evidence of smoke from forest fires inhibiting rainfall. Geophys. Res. Lett., 26, 3105-3108.

— 2000: Suppression of rain and snow by urban air pollution. Science, 287, 1793-1796.

Rozoff, C., W. R. Cotton, and J. O. Adegoke, 2003: Simulation of St. Louis, Missouri, land use impacts on thunderstorms. J. Appl. Meteor., 42, 716-738.

Schultz, P., 1995: On explicit cloud physics parameterization for operational numerical weather prediction. Mon. Wea. Rev., 123, 3321-3343.

Selover, N., 1997: Precipitation patterns around an urban desert environment topographic or urban influences? Proc. Association of American Geographers Convention, Fort Worth, TX, Association of American Geographers.

Shepherd, J. M., and S. J. Burian, 2003: Detection of urban-induced rainfall anomalies in a major coastal city. Earth Interactions, 7. [Available online at http://EarthInteractions.org.]

— Eos, Trans. Amer. Geophys. Union, 85, 227-228.

— H. Pierce, and A. J. Negri, 2002: Rainfall modification by major urban areas: Observations from spaceborne rain radar on the TRMM satellite. J. Appl. Meteor., 41, 689-701.

— L. Taylor, and C. Garza, 2004: A dynamic multi-criteria technique for siting NASA-Clark Atlanta rain gauge network. J. Atmos. Oceanic Technol., 21, 1346-1363.

Shreffler, J. H., 1978: Detection of centripetal heat-island circulations from tower data in St. Louis. Bound.-Layer Meteor., 15, 229-242.

Steiger, S. M., and R. E. Orville, 2003: Cloud-to-ground lightning enhancement over southern Louisiana. Geophys. Res. Lett., 30, 1975, doi:10.1029/2003GL017923.

- _ _ - and G. Huffines, 2002: Cloud-to-ground lightning characteristics over Houston, Texas: 1989-2000. J. Geophys. Res., 107, 4117, doi:10.1029/2001JD001142.

Takahashi, H., 2003: Secular variation in the occurrence property of summertime daily rainfall amount in and around the Tokyo Metropolitan area (in Japanese with an English abstract). Tenki, 50, 31-41.

Tao, W.-K., and J. Simpson, 1993: The Goddard cumulus ensemble model. Part I: Model description. Terr. Atmos. Oceanic Sci., 4, 35-72.

Tayanç, M., M. Karaca, and O. Yenigün, 1997: Annual and seasonal air temperature trend patterns of climate change and urbanization effects in relation to air pollutants in Turkey. J. Geophys. Res., 102 (D2), 1909-1920.

Thielen, J., W. Wobrock, A. Gadian, P. G. Mestayer, and J.-D. Creutin, 2000: The possible influence of urban surfaces on rainfall development: A sensitivity study in 2D in the mesogamma scale. Atmos. Res., 54, 15-39.

UNFP, 1999: The State of World Population 1999. United Nations Population Fund, United Nations Publications, New York, 76 pp.

Vukovich, F. M., and J. W. Dunn, 1978: A theoretical study of the St. Louis heat island: Some parameter variations. J. Appl. Meteor., 17, 1585-1594. 


\author{
Earth Interactions • Volume 9 (2005) • Paper No. 12 • Page 27
}

Wetzel, P., and A. Boone, 1995: A Parameterization for Land-Atmosphere-Cloud Exchange (PLACE): Documentation and testing of a detailed process model of the partly cloudy boundary layer over a heterogeneous land. J. Climate, 8, 1810-1837.

Yoshikado, H., 1994: Interaction of the sea breeze with urban heat islands of different sizes and locations. J. Meteor. Soc. Japan, 72, 139-142.

Earth Interactions is published jointly by the American Meteorological Society, the American Geophysical Union, and the Association of American Geographers. Permission to use figures, tables, and brief excerpts from this journal in scientific and educational works is hereby granted provided that the source is acknowledged. Any use of material in this journal that is determined to be "fair use" under Section 107 or that satisfies the conditions specified in Section 108 of the U.S. Copyright Law (17 USC, as revised by P.IL. 94-553) does not require the publishers' permission. For permission for any other form of copying, contact one of the copublishing societies. 
Copyright of Earth Interactions is the property of American Meteorological Society. The copyright in an individual article may be maintained by the author in certain cases. Content may not be copied or emailed to multiple sites or posted to a listserv without the copyright holder's express written permission. However, users may print, download, or email articles for individual use. 